Article

\title{
Analysis of the Guide Vane Jet-Vortex Flow and the Induced Noise in a Prototype Pump-Turbine
}

\author{
Ran Tao and Zhengwei Wang * \\ Department of Energy and Power Engineering, Tsinghua University, Beijing 100084, China; \\ randytao@mail.tsinghua.edu.cn \\ * Correspondence: wzw@mail.tsinghua.edu.cn
}

Received: 28 March 2019; Accepted: 10 May 2019; Published: 14 May 2019

Featured Application: This work provides a way to visualize the pressure pulsation signal in turbomachinery flow case. It can be also used in all the engineering CFD cases.

\begin{abstract}
The start-up process of a pump-turbine in pump mode is found with obvious noise, especially at the small guide vane opening angle. The turbulent-flow-induced noise is an important part and must be reduced by flow control. Therefore, the computational fluid dynamics (CFD) method is used in this study to predict the internal flow in a high head prototype pump-turbine (the specific speed $n_{q}$ is 31.5) under an extremely off-design condition $\left(C_{\varphi}=0.015\right.$ and $\left.C_{\alpha}=0.096\right)$. The acoustic analogy method is also used to predict the near-field noise based on the turbulence field. Special undesirable flow structures including the flow ring between the runner trailing-edge and the guide vane, guide vane jet, twin-vortexes adjacent to guide vane jet, inter stay vane vortex, stay vane jet, and volute vortex-ring are found in a pump-turbine. These complex jet-vortex flow structures induce local high turbulence kinetic energy and an eddy dissipation rate, which is the reason why noise is generated at small guide vane opening angle. Three dominating frequencies are found on the turbulence kinetic energy pulsation. They are the runner blade frequency $f_{b}=64.5 \mathrm{~Hz}$, the dominate frequency in the guide vane and the stay vane $f_{g s v}=9.6 \mathrm{~Hz}$, and the dominate frequency in volute $f_{v l}=3.2 \mathrm{~Hz}$. The flow pulsation tracing topology gives a good visualization of frequency propagation. The dominating regions of the three specific frequencies are clearly visualized. Results show that different flow structures may induce different frequencies, and the induced specific frequencies will propagate to adjacent sites. This study helps us to understand the off-design flow regime in this prototype pump-turbine and provides guidance when encountering the noise and stability problems during pump mode's start-up.
\end{abstract}

Keywords: pump-turbine; jet-vortex flow; guide vane opening; flow-induced noise; frequency propagation

\section{Introduction}

A reversible pump-turbine is the key component in pumped storage power station [1]. It has complex varying operation conditions due to frequent starting and stopping [2]. The rotating runner, adjustable guide vane, and stay vane may cause strong rotor-stator interaction and stalled flow [3,4]. Undesirable flow regimes, including secondary flow, vortex, back flow, and submerged jet flow, could occur inside a pump-turbine [5-7]. The noise induced by undesirable flow structures is one of the bad factors occurring during operation [8]. It also represents a part of the energy dissipation [9]. During the operation of the prototype pump-turbine, high intensity noise is often found, especially in the pump mode's start-up process with a small guide vane opening angle. When focusing on this noise phenomenon, complex sources can be found, including flow-induced noise and mechanical noise [10]. The mechanical noise can be reduced by conducting better design and manufacturing. 
However, the flow-induced noise is more complex to handle. There are different types of flow-induced noise-mainly, the turbulent-flow-induced noise [11] and the cavitation bubble collapse noise [12]. The turbulent-flow-induced noise exists in almost all the flow conditions and needs specific studies.

In bladed turbomachinery, the acoustic topic has received long-time extensive investigations [13-15]. For numerical simulations, there are two main ways to predict the flow-induced noise. One is the direct solving of the Navier-Stokes equations. This is accurate but requires a high computer cost. Another one is the acoustic analogy method [16]. This predicts the near-field by the computational fluid dynamics (CFD) method and extends to the far-field by computational acoustic (CA) method. Based on the methods above, researchers conducted numerical studies for the acoustic characters in bladed turbomachinery. It was found that the rotor-stator interaction could induce flow noise [17]. The distance between rotor and stator would strongly affect the noise intensity [18]. A rotating stall cell was also proved as one of the source of flow noise $[19,20]$. The jet flow was found as another local high noise region [21,22]. The blade exit wake also generated noise due to periodic shedding $[23,24]$. Generally, the local flow regime is complex in turbomachinery and may cause the noise problem.

In this study, a prototype reversible pump-turbine was studied on its turbulent-flow field and induced noise during pump mode's start-up. Proudman [25] introduced the simulation method of turbulent-flow-induced noise, considering the turbulence isotropic assumption. Based on a prediction of the turbulence kinetic energy and dissipation rate, the local sound power distribution can be evaluated [26]. The reason for turbulent-flow-induced noise in a pump-turbine can be clarified in detail. As a widely-used, robust, and accurate method, CFD simulation is useful for predicting the turbomachinery flow cases. Currently, a lot of CFD based studies have been conducted in the pump-turbines for the flow regime [27,28], performance [29,30], cavitation [31], and stability problems [32,33]. These numerical results were compared with the tests and proved reliable and convenient. In this case, CFD simulation was used for the prototype pump-turbine. The partial-load condition with a small guide vane opening angle during pump mode's start-up was studied. The noise caused by the special jet-vortex flow regime and its transient variation is discussed in detail. As a difficult issue in hydraulic turbomachinery flow cases, the flow mechanism at the off-design condition is also discussed in this study. The results provide a basis for understanding the flow noise and energy dissipation at partial-load in pump mode. It also reveals the flow complexity when a pump-turbine operates off-design. The relationship between the operation condition and the turbulent flow regime is also clarified. This will help the noise reduction, loss reduction, and efficiency enhancement of reversible pump-turbines.

\section{Pump-Turbine Unit}

\subsection{Parameters of Pump-Turbine}

Figure 1 is the schematic map of the pump-turbine (fluid domain in prototype scale) which consists of the draft tube, runner, guide vane, stay vane, and volute. Fluid, as indicated by the vector, flows from the draft tube side to volute side in pump mode for water storage. The runner rotates in the clockwise direction in this view by $n_{d}=430 \mathrm{r} / \mathrm{min}$. As shown in the meridional view, the radius at runner high pressure side is $R_{h i}=2.08 \mathrm{~m}$. The radii at runner low pressure side $R_{\text {lows }}$ (at shroud) and $R_{\text {lowh }}$ (at hub) are $1.12 \mathrm{~m}$ and $0.64 \mathrm{~m}$, respectively. The width at runner outlet $b_{h i}$ is $0.4 \mathrm{~m}$. The blade number of the runner, guide vane, and stay vane are 9,20 , and 20, respectively. Based on the turbomachinery similarity, the specific speed of runner $n_{q}$ can be calculated by:

$$
n_{q}=\frac{n_{d} \sqrt{Q_{d}}}{H_{d}^{3 / 4}}
$$

where $Q_{d}$ is the best efficiency point (BEP) flow rate and $H_{d}$ is the BEP head. In this case, the specific speed $n_{q}$ is equal to 31.5 . 


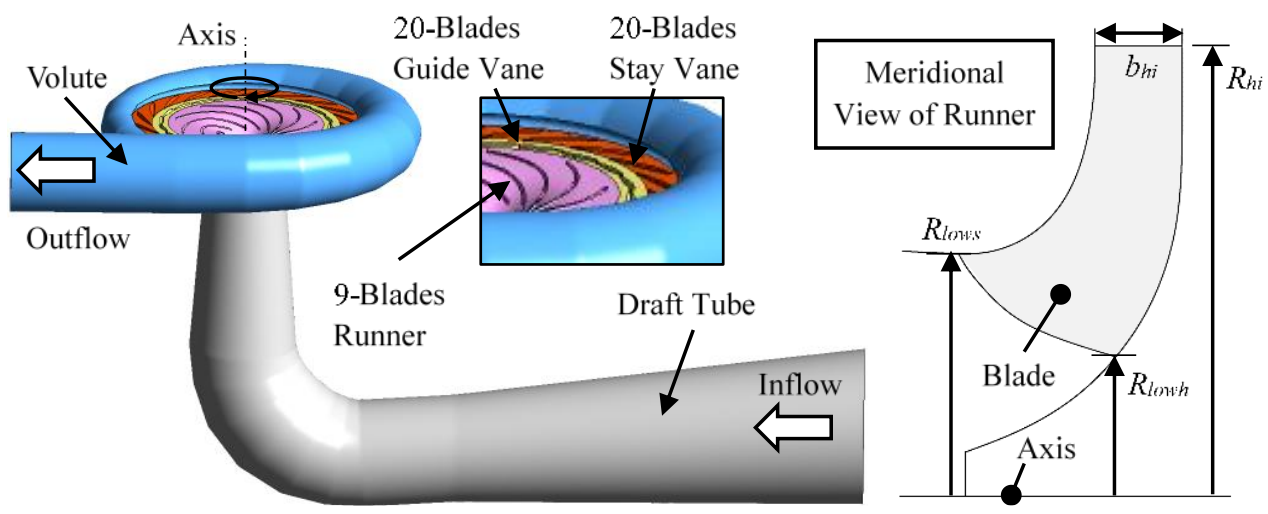

Figure 1. The schematic map of the pump-turbine in prototype scale shown as a fluid domain.

\subsection{Studied Condition}

A partial-load condition in pump mode is numerically studied in this case. It is indicated in Figure 2 based on the model-tested high efficiency on-cam $C_{\varphi}-C_{\alpha}$ conditions. $C_{\varphi}$ is the flow rate coefficient which can be expressed as:

$$
C_{\varphi}=\frac{Q}{\pi \omega R_{h i}^{3}}
$$

where $Q$ is the flow rate and $\omega$ is the rotational angular speed. $C_{\alpha}$ is the relative guide vane opening angle which can be defined as:

$$
C_{\alpha}=\frac{\alpha}{\alpha_{\max }}
$$

where $\alpha$ is the guide vane opening angle and $\alpha_{\max }$ is the maximum guide vane opening angle of 31 degrees. According to Figure 2, this numerically studied condition is about $35 \%$ of the best efficiency flow rate condition $\left(C_{\varphi B E P}=0.043\right)$. The guide vane opening angle is about $9.6 \%$ of the maximum value. This studied condition, $C_{\varphi}=0.015$ and $C_{\alpha}=0.096$, is in the pump mode's start-up process which may have a complex internal flow regime and strong flow instability. CFD is used to predict the turbulent-flow-induced noise and analyze the mechanism in detail. For convenience, this studied condition is denoted as $C_{1}$ in the following sections.

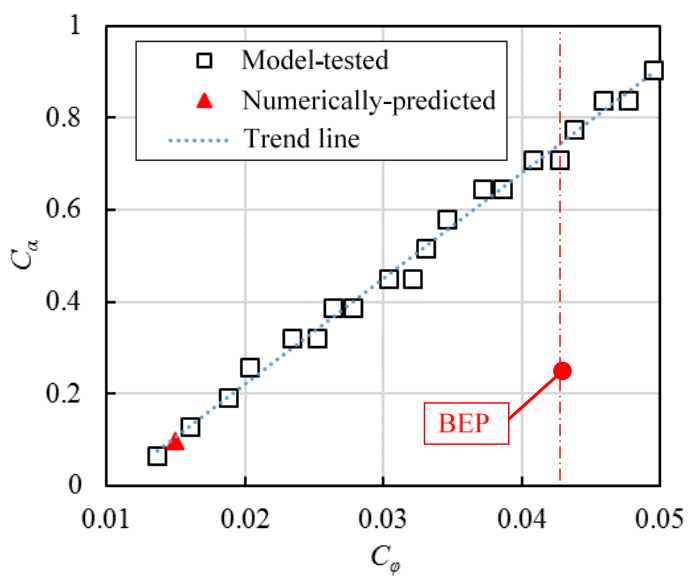

(a)

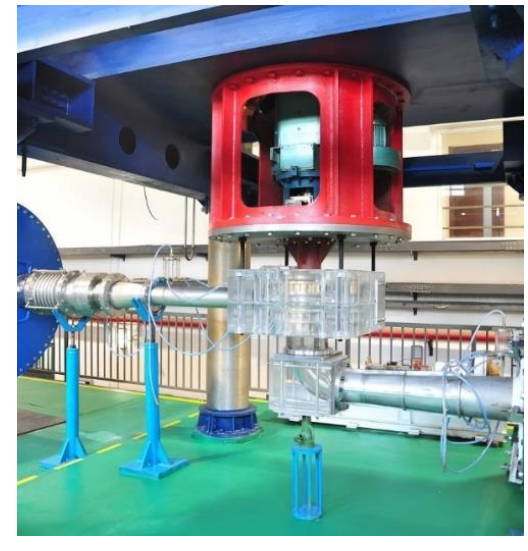

(b)

Figure 2. The selection and determination of the numerically studied condition based on model test. BEP: best efficiency point. (a) The on-cam relationship between $C_{\varphi}$ and $C_{\alpha}$ based on model test; (b) the model test rig. 


\section{Mathematical Modeling}

\subsection{Governing Equations}

In this numerical case, the three-dimensional incompressible viscous flow was considered by solving the Reynolds-averaged Navier-Stokes (RANS) equations. The continuity equation and momentum equation can be written as:

$$
\begin{gathered}
\overline{\frac{\partial u_{i}}{\partial x_{i}}}=0 \\
\rho \frac{\partial \overline{u_{i}}}{\partial t}+\rho \overline{u_{j}} \frac{\partial \overline{u_{i}}}{\partial x_{j}}=\frac{\partial}{\partial x_{j}}\left(-\bar{p} \delta_{i j}+2 \mu \overline{S_{i j}}-\rho \overline{u_{i}^{\prime} u_{j}^{\prime}}\right)
\end{gathered}
$$

where $u$ velocity, $t$ is time, $\rho$ is density, $x$ is coordinate component, $\delta_{i j}$ is the is the Kroneker delta, and $\mu$ is the dynamic viscosity. $\bar{\phi}$ and $\phi^{\prime}$ are the averaged and fluctuating components of arbitrary variable. $\overline{S_{i j}}$ is the mean rate of strain tensor:

$$
\overline{S_{i j}}=\frac{1}{2}\left(\frac{\partial \overline{u_{i}}}{\partial x_{j}}+\frac{\partial \overline{u_{j}}}{\partial x_{i}}\right)
$$

\subsection{Turbulence Modeling}

To close the RANS equations, eddy viscosity $\mu_{t}$ can be used to build the relationship between Reynolds stress $\rho \overline{u_{i}^{\prime} u_{j}^{\prime}}$ and the mean rate of strain tensor by:

$$
-\rho \overline{u_{i}^{\prime} u_{j}^{\prime}}=2 \mu_{t} \overline{S_{i j}}-\frac{2}{3} k \delta_{i j}
$$

where $k$ is the turbulence kinetic energy. The shear stress transport model based Detached Eddy Simulation (SST-DES) method is used for turbulent flow modeling. It is a zonal hybrid method [34] based on the Reynolds-averaged Navier-Stokes (RANS) equations and Large-Eddy Simulation (LES) equations. The SST model is used as the turbulence model for the time-averaged equations [35]. In the SST model, the turbulence kinetic energy $k$ equation and specific dissipation rate $\omega$ equation can be specified as:

$$
\begin{gathered}
\frac{\partial(\rho k)}{\partial t}+\frac{\partial\left(\rho u_{i} k\right)}{\partial x_{i}}=P-\frac{\rho k^{3 / 2}}{l_{k-\omega}}+\frac{\partial}{\partial x_{i}}\left[\left(\mu+\sigma_{k} \mu_{t}\right) \frac{\partial k}{\partial x_{i}}\right] \\
\frac{\partial(\rho \omega)}{\partial t}+\frac{\partial\left(\rho u_{i} \omega\right)}{\partial x_{i}}=C_{\omega} P-\beta \rho \omega^{2}+\frac{\partial}{\partial x_{i}}\left[\left(\mu_{l}+\sigma_{\omega} \mu_{t}\right) \frac{\partial \omega}{\partial x_{i}}\right]+2\left(1-F_{1}\right) \frac{\rho \sigma_{\omega 2}}{\omega} \frac{\partial k}{\partial x_{i}} \frac{\partial \omega}{\partial x_{i}}
\end{gathered}
$$

where $l_{k-\omega}$ is the turbulence scale, which can be expressed as:

$$
l_{k-\omega}=k^{1 / 2} \beta_{k} \omega
$$

in which $P$ is the production term, $C_{\omega}$ is the coefficient of the production term, $F_{1}$ is the blending function, and $\sigma_{k}, \sigma_{\omega}$, and $\beta_{k}$ are the model constants. In the DES method, the term $\min \left(l_{k-\omega}, C_{D E S} \Delta_{m}\right)$ is used instead of simple $l_{k-\omega}$ term where $\Delta_{m}=\max (\Delta x, \Delta y, \Delta z)$ is the mesh length scale, which is the maximum side length of an mesh element. If $l_{k-\omega}<C_{D E S} \Delta$, the LES model will be used instead of the RANS model for modeling the turbulence flow field.

As widely known, turbulent flow in turbomachinery is mainly anisotropic. The SST model and other eddy viscosity models are based on the turbulence isotropic assumption. It can be somehow correct in engineering cases, but it lacks accuracy, especially in modeling local secondary flows. Corrections or improvements can be supplied for eddy viscosity models to have a better simulation. Therefore, DES is used to have a better solution of the jet and vortex flow field in this study. It may improve the simulation mainly in the large scale eddies. By predicting the Reynolds number (about $2.8 \times 10^{6}$ ) and approximately calculating the upstream freestream velocity at the draft tube inlet (about 
$1.2 \mathrm{~m} / \mathrm{s}$ ), one is able to solve out the viscous length scale (about $0.017 \mathrm{~mm}$ ). On one hand, the largest longitudinal eddy scale is about 30 300 times the viscous length scale. It is from about $0.5 \mathrm{~mm}$ to about $5 \mathrm{~mm}$. On the other hand, the eddy scale of turbulence kinetic energy dissipation is about $4 \sim 8$ times of the viscous length scale. It is about $0.066 \sim 0.132 \mathrm{~mm}$. Considering the balance computation cost and accuracy, the DES model is mainly used for resolving the $0.5 \sim 5 \mathrm{~mm}$ eddies by applying a suitable mesh length scale $\Delta_{m}$. The effectiveness of DES will be checked and discussed after analyzing the results.

\subsection{Acoustic Analogy Method}

In this case, the acoustic analogy method $[25,36]$ was used based on turbulence modeling by calculating the near-field of turbulent-flow-induced sound power $W_{A}$ as:

$$
W_{A}=\alpha_{\varepsilon} \rho \varepsilon\left(\frac{\sqrt{2 k}}{V_{c}}\right)^{5}
$$

where $\alpha_{\varepsilon}$ is a constant of $0.1, \varepsilon$ is the eddy dissipation rate, and $V_{c}$ is the sound speed in fluid medium. The turbulent-flow-induced sound power level $L_{s p}$ can be calculated by:

$$
L_{s p}=10 \log _{10}\left(\frac{W_{A}}{W_{r e f}}\right)
$$

where $W_{\text {ref }}$ is the reference sound power. In this study, water at $20^{\circ} \mathrm{C}$ was used as the fluid medium so that $V_{c}$ was $1500 \mathrm{~m} / \mathrm{s}$ and $W_{\text {ref }}$ was about $6.7 \times 10^{-19} \mathrm{~W} / \mathrm{m}^{3}$.

\section{CFD Setup}

Based on the fluid domain shown in Figure 1, the computational fluid dynamics (CFD) simulation was conducted using the commercial code CFX in ANSYS (v18, Pittsburgh, PA, USA). The mesh used in the CFD simulation was done by using ICEMCFD with structural hexahedral elements and checked in size and in $y^{+}$. The mesh size was checked by using the grid convergence index (GCI) method [37] at the condition $\mathrm{C}_{1}$. The pressure difference between the volute outlet and draft tube inlet was selected as the index. Three mesh schemes with $1^{\prime} 062^{\prime} 882,2^{\prime} 813^{\prime} 808$, and $6^{\prime} 511^{\prime} 958$ nodes were GCI-checked with the discretization uncertainty of $5.5 \%$, which is smaller than the limit of acceptance limit of $10 \%$ [37]. Thus, the final mesh scheme had $6^{\prime} 511^{\prime} 958$ nodes to balance the accuracy and the computational cost. The $y^{+}$value on all the walls was controlled between 0.27 and 9.13 for applying the automatic wall-function [38] by refining the near-wall first layer height. The detail of mesh node number is shown in Figure 3. To capture the complex undesirable flow regime, especially from the runner outlet to the stay vane outlet, the mesh node density in these regions were specifically refined.

The multiple reference frame (MRF) model [39] was used where the draft tube, guide vane, stay vane, and volute were stationary, and the runner was rotational by $n_{d}=430 \mathrm{r} / \mathrm{min}$. The fluid medium, which is mentioned above, was set as water at $20^{\circ} \mathrm{C}$, with a molar mass of $18.02 \mathrm{~g} / \mathrm{mol}$, density of $997 \mathrm{~kg} / \mathrm{m}^{3}$, dynamic viscosity of $8.899 \times 10^{-4} \mathrm{~kg} / \mathrm{m} \cdot \mathrm{s}$. The environment pressure was set as $1 \mathrm{Atm}$. The boundary conditions are given as follows:

- A velocity inlet boundary was given at the draft tube inflow with uniformly distributed value.

- A static pressure outlet boundary of 0 Pa was given at the volute outflow.

- No-slip wall boundaries were given on all the solid walls.

- Interfaces were set for connecting different domains based on the general grid interface method. The "frozen rotor" type was used for the rotor-stator interface in steady state simulations. The "transient rotor stator" type was used for transient simulations. 


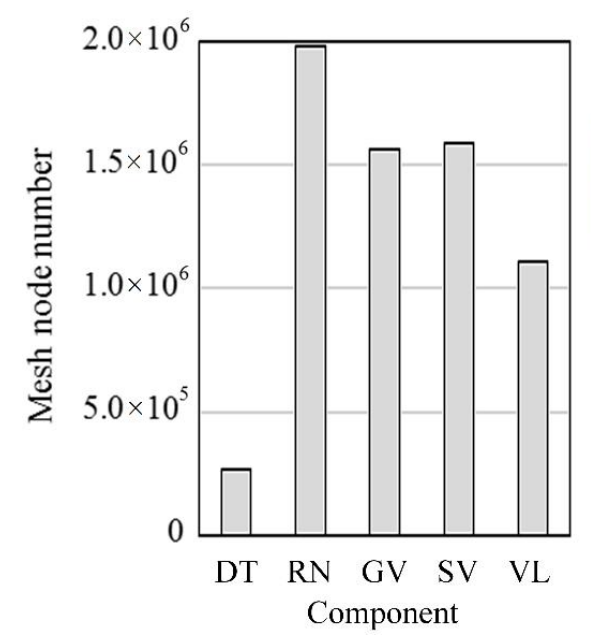

(a)

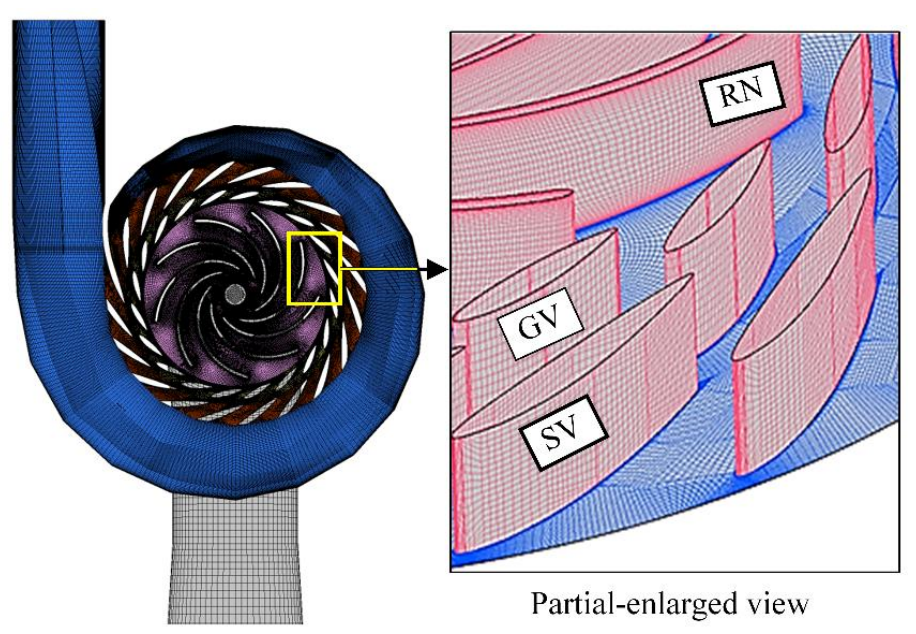

(b)

Figure 3. Mesh node number of all the flow components with an enlarged view of the mesh from the runner outlet to the stay vane outlet. DT: Draft tube; RN: Runner; GV: Guide vane; SV: Stay vane; VL: Volute. (a) Mesh node number of all the components; (b) schematic map of mesh.

Both the steady state and transient simulations were conducted. The steady state simulation was the initial simulation by 600 steps. It converged based on the criterion of root-mean-square (RMS) residuals of the continuity and momentum equations of less than $1 \times 10^{-5}$. The transient simulation was based on the steady state results. More than 5 runner revolutions were simulated. In one runner revolution, 720 time steps were conducted. At most, 10 iterations were allowed for the convergence of each time step based on the convergence criterion of RMS residuals of less than $1 \times 10^{-6}$. The discrete form of the advection term in both the momentum equation and the turbulent transport equation were set as high resolution. Based on the guide vane opening angle law shown in Figure 2, the mesh scheme and numerical setup above were verified by comparing them with the model-test. Because the internal flow regime is unable to capture in model-test, the efficiency $\eta$ was chosen for verification. The numerical $C_{\varphi}-\eta$ data was compared with experimental $C_{\varphi}-\eta$ data, as shown in Figure 4. The 4 compared conditions include the objective condition $C_{1}$, the best efficiency condition, another partial-load condition, and another over-load condition. The same tendency can be observed. It proves that the mesh scheme and numerical setup is somehow reliable for flow mechanism analysis.

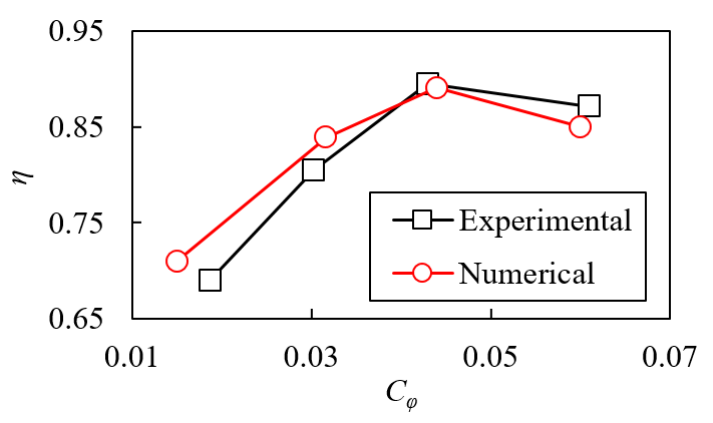

Figure 4. Verification for mesh scheme and numerical setup by comparing the $C_{\varphi-} \eta$ data.

\section{Results and Analysis}

\subsection{Reference Positions for Post-Processing}

To analysis the internal flow regime at condition $C_{1}$, two reference surfaces were built, as shown in Figure 5 based on the $X Y Z$ orthogonal coordinate. Surface $S_{A}$ includes the mid-span of the runner, 
guide vane, stay vane, and mid- $X Y$-section of volute. Surface $S_{B}$ is the mid-XZ-section of all the components. The specific position on $S_{B}$ is also indicated for analyzing the flow on the volute section.

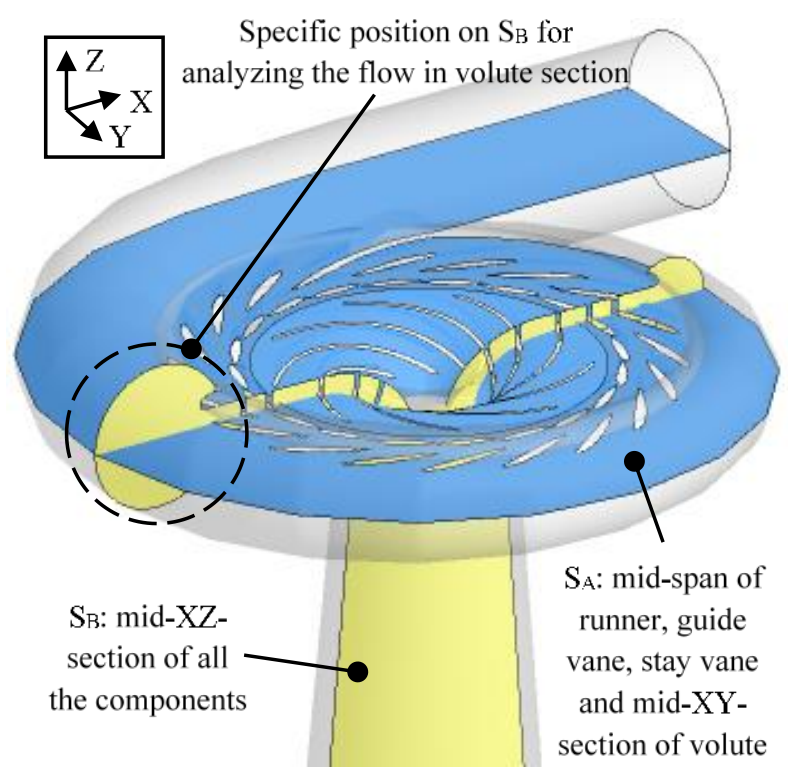

Figure 5. Reference surfaces $S_{A}$ and $S_{B}$ for flow field plotting.

\subsection{Internal Flow Regime}

Figure 6 shows the flow regime on $S_{A}$ by plotting the $C_{v}$ vectors where $C_{v}$ is the velocity coefficient:

$$
C_{v}=\frac{V_{\text {rel }}}{U_{h i}}
$$

where $V_{\text {rel }}$ is the relative velocity and $U_{h i}$ is the rotational linear velocity at $R_{h i}$.

As indicated by the vectors and numbers I-VII, there are seven special flow regimes on $\mathrm{S}_{\mathrm{A}}$. Number I is the flow ring between the runner trailing-edge and guide vane. Due to the small guide vane opening angle, the passing ability is poor at condition $C_{1}$. However, the runner is continually pumping with the full rotation speed of $430 \mathrm{r} / \mathrm{min}$. Therefore, most of the pumped water cannot pass through the guide vane but can keep rotating as a water ring there.

The guide vane jet is denoted by number II. Numbers III and IV are the twin-vortexes adjacent to the jet. Because of the runner pumping, some water passes through the guide vane leakage and is generated as a high-speed jet. The guide vane jet hits on the stay vane blade and causes two individual vortexes on the two sides. The vortex number III rotated clockwise, which is the same as the runner rotation direction. On the contrary, the vortex number IV rotates counter-clockwise.

Number $\mathrm{V}$ is the inter stay vane vortex, which occupies almost the entire stay vane channel. However, a stay vane jet flow denoted as number VI can be observed along the concave surface of the stay vane surface. After the guide vane jet hits on the stay vane blade, it keeps going, generates as the stay vane jet and passes through the stay vane channel. Then, the stay vane jet flow flows into the volute with high-speed.

Number VII is the volute vortex-ring. The generation of the vortex-ring can be observed in Figure $7 \mathrm{~b}$ on surface $S_{B}$. There are two symmetrical rotating flow structures in volute. The two rotating flow structures interfere with each other and block the stay vane outlet. However, the high-speed stay vane jet can go across the vortex-ring and divides the vortex-ring into individual parts. As shown in Figure $7 \mathrm{a}$, the stay vane jet flows into the volute. The two symmetrical rotating flow structures still exist. 

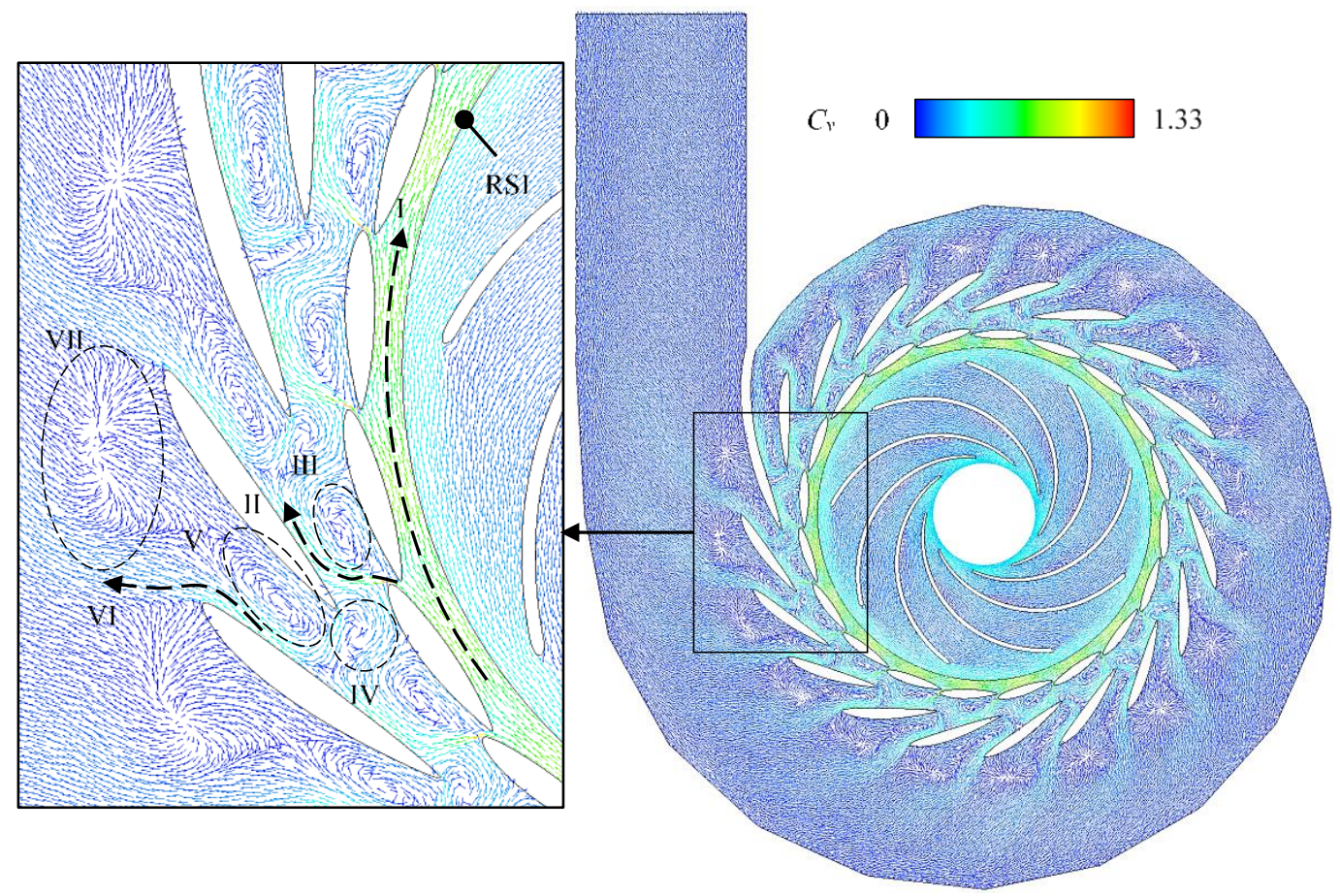

Figure 6. Flow regime on $S_{A}$ by plotting the $C_{v}$ vectors. I: Flow ring between the runner trailing-edge and the guide vane; II: Guide vane jet; III and IV: Twin-vortexes adjacent to guide vane jet; V: Inter stay vane vortex; VI: Stay vane jet; VII: Volute vortex-ring; RSI: Rotor-stator interface.

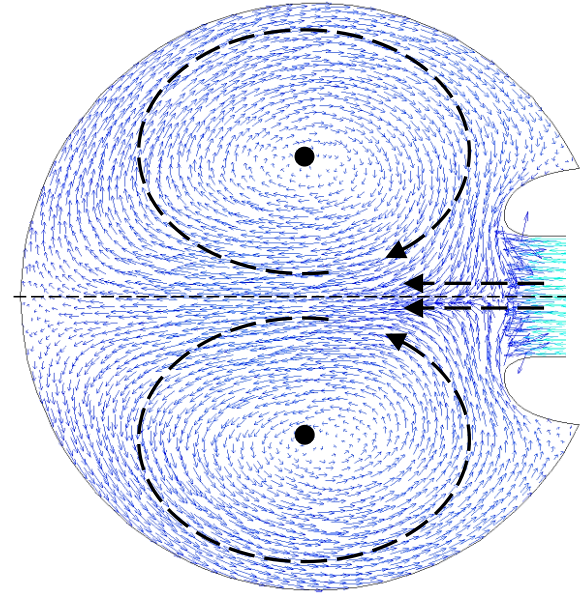

(a)

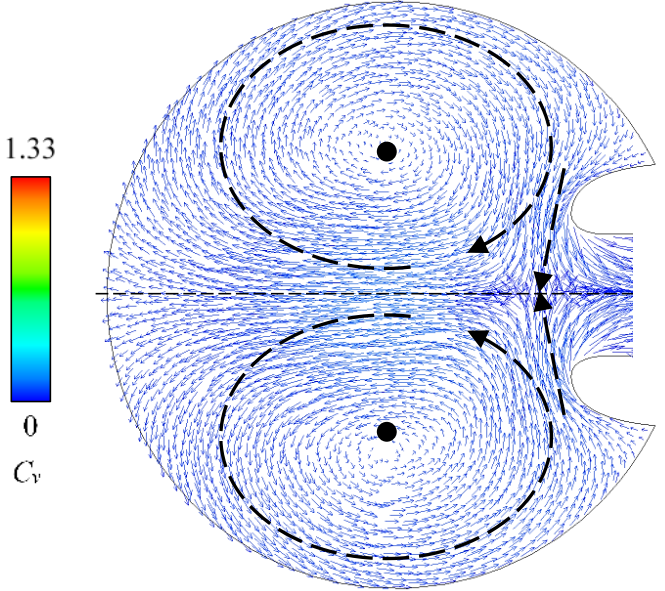

(b)

Figure 7. Flow regime on $S_{B}$ in volute at different locations by plotting the $C_{v}$ vectors. (a) Section across the stay vane jet; (b) section across the volute vortex.

\subsection{Instaneous Turbulent-Flow-Induced Noise Field}

Based on the $S_{A}$ and $S_{B}$ surfaces, the instaneous turbulent-flow-induced noise fields were analyzed. Figure 8 shows the instaneous turbulent-flow-induced noise field on $S_{A}$ by plotting the $L_{s p}$ contour. The indication numbers I to VII are kept on this figure. In the number I region in which the flow ring is between the runner trailing-edge and the guide vane, the $L_{s p}$ value is around $80 \mathrm{~dB}$. This is not a high noise region. The guide vane jet region number II is the highest $L_{s p}$ region on $\mathrm{S}_{\mathrm{A}}$. The value of $L_{s p}$ is up to $150 \mathrm{~dB}$. In the twin-vortexes region numbers III and IV, $L_{s p}$ becomes higher to about 100 120 dB. However, a low $L_{s p}$ value lower than $90 \mathrm{~dB}$ can be also observed in the vortex core region of number IV. 
This means that the clockwise rotating vortex produces more noise than the counter-clockwise rotating vortex. The inter stay vane vortex number $\mathrm{V}$ and the stay vane jet flow number VI are also high $L_{s p}$ regions. The local highest $L_{s p}$ value is in the stay vane vortex core region and reached about $130 \mathrm{~dB}$. The value of $L_{s p}$ in the volute vortex ring number VII region decreases to about $80 \sim 100 \mathrm{~dB}$. However, it is also higher than in the other parts of volute. Based on Figure $9 b$, it can be seen that the local highest $L_{s p}$ value is in the volute vortex core region. If the stay vane jet flows across the volute vortex ring, the local highest $L_{s p}$ region disappears. $L_{s p}$ is relatively high on the symmetry axis due to upper-lower flow interference.

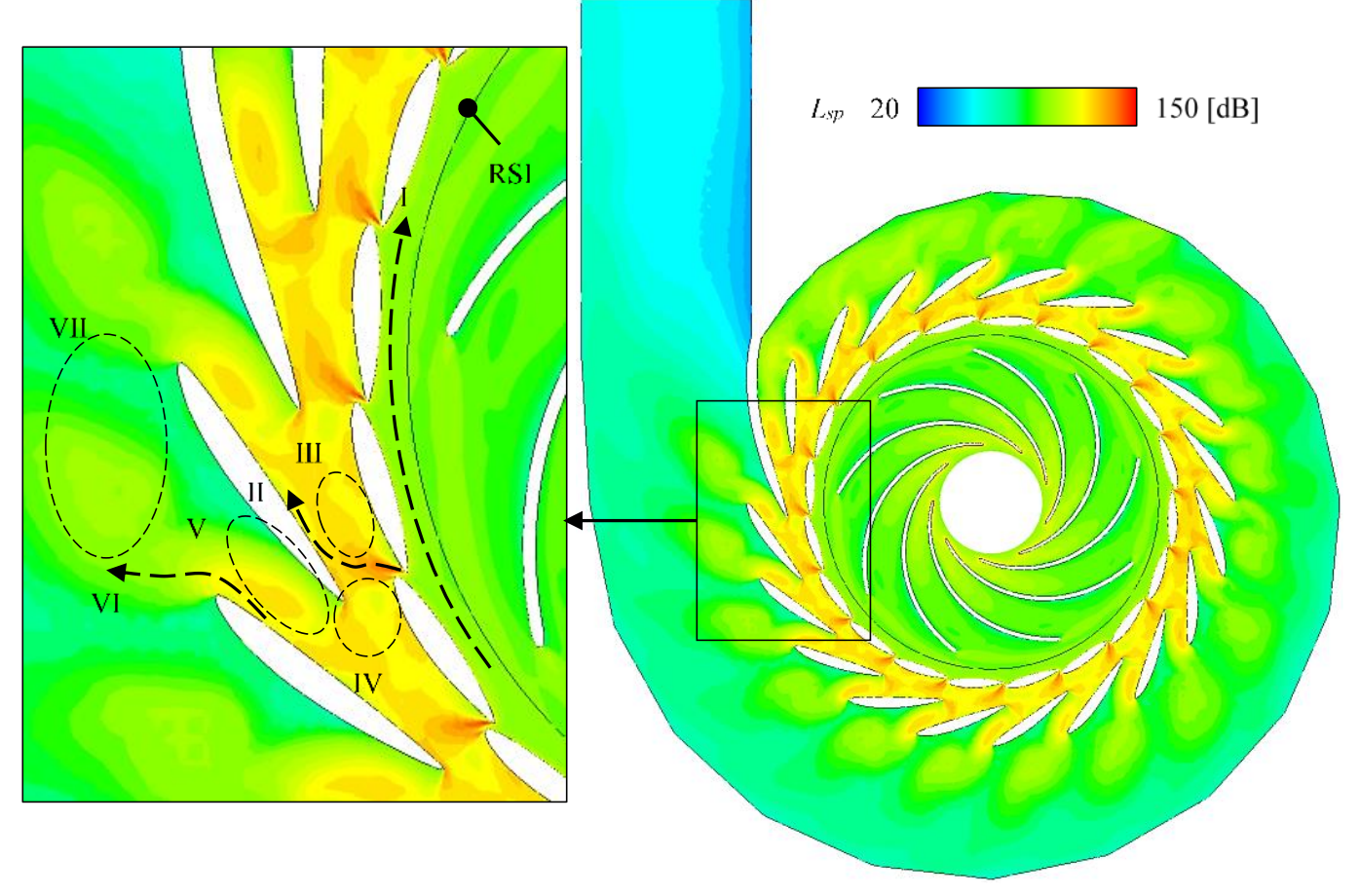

Figure 8. Instaneous turbulent-flow-induced noise field on $\mathrm{S}_{\mathrm{A}}$ by plotting the $L_{s p}$ contour. I: Flow ring between the runner trailing-edge and the guide vane; II: Guide vane jet; III and IV: Twin-vortexes adjacent to guide vane jet; V: Inter stay vane vortex; VI: Stay vane jet; VII: Volute vortex-ring; RSI: Rotor-stator interface.

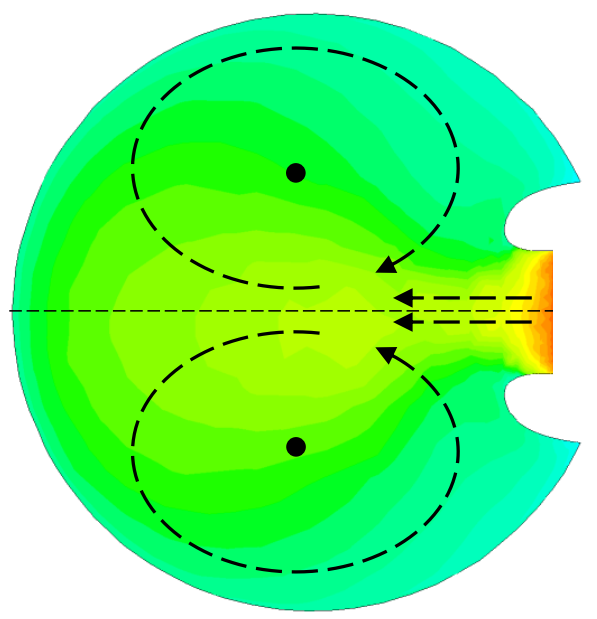

(a)

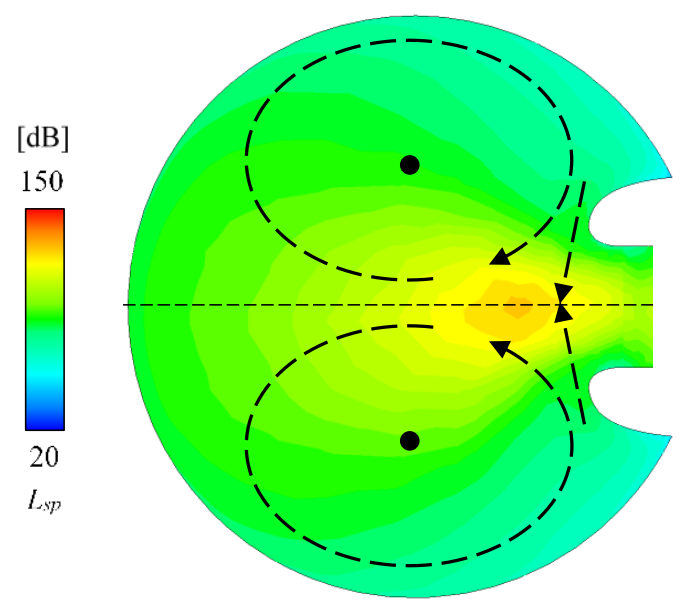

(b)

Figure 9. Instaneous turbulent-flow-induced noise field on $S_{B}$ in volute at different locations by plotting the $L_{s p}$ contour. (a) Section across the stay vane jet; (b) section across the volute vortex. 
Local high $L_{s p}$ regions can be also found on the runner blade leading-edge, even if there is no obvious undesirable flow pattern. Figure 10 indicates the $L_{s p}$ contours on the runner blade leading-edge, guide vane blade leading-edge, and stay vane blade leading-edge. Similarities can be found in that the leading-edge regions are all in high $L_{s p}$. Specifically, two high $L_{s p}$ regions can be found on one guide vane blade's leading-edge and on another guide vane blade's trailing-edge. On the contrary, the inter guide vane region where jet flow already generates is low in $L_{s p}$. Thus, the local flow striking and separation are the reasons why flow noise generates.

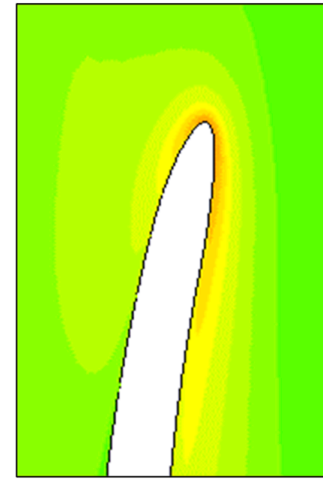

(a)

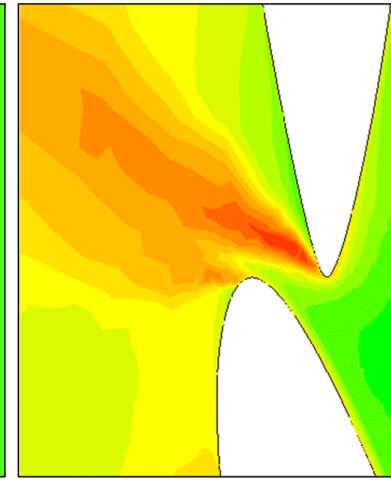

(b)

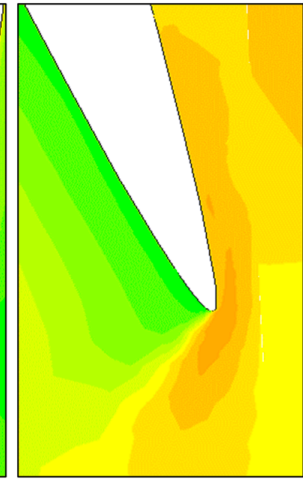

(c)

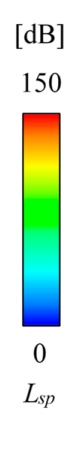

Figure 10. Local high $L_{s p}$ regions on the blade leading-edges. LE: Leading-edge. (a) Runner leading-edge; (b) Guide vane leading-edge and trailing-edge; (c) Stay vane leading-edge.

According to Equation (11), the turbulent-flow-induced noise strongly relates to the turbulence kinetic energy $k$ and eddy dissipation rate $\varepsilon$. To understand the reason why noise is generated in turbulent flow, the distribution of $k$ and $\varepsilon$ can be studied. The dimensionless turbulence kinetic energy coefficient $C_{k}$ is used:

$$
C_{k}=\frac{k}{2 g R_{h i}}
$$

where $g$ is the acceleration of gravity. The dimensionless eddy dissipation rate coefficient $C_{\varepsilon}$ is defined as:

$$
C_{\varepsilon}=\frac{\varepsilon^{2}}{g^{3} R_{h i}}
$$

The square value of $\varepsilon$ is used because $k$ and $\varepsilon^{2}$ contribute to the same extent in predicting the turbulence-induced-noise using Equation (11). Figure 11 shows the comparison of $L_{s p}, C_{k}$, and $C_{\varepsilon}$ contours.

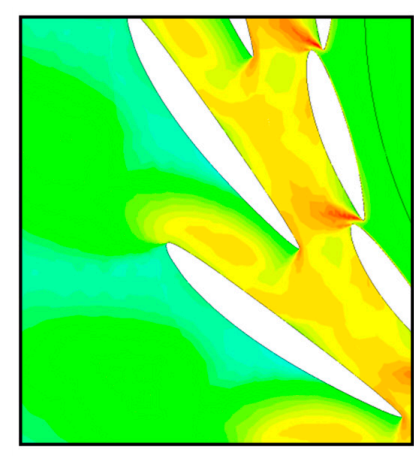

$L_{s p} 0$

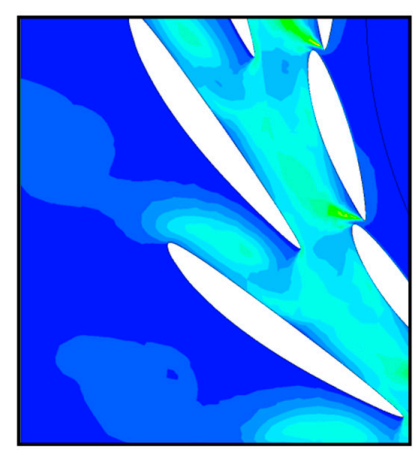

$C_{k} 0$

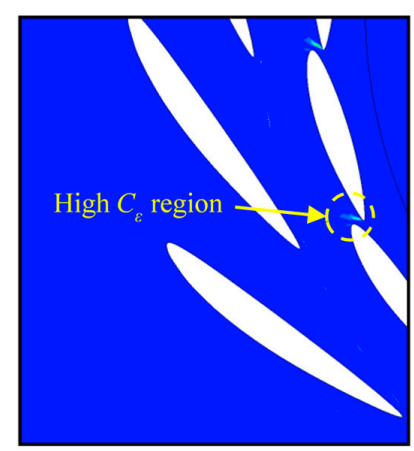

$C_{\varepsilon} 0$

(a)

(b)

(c)

Figure 11. Comparison of $L_{s p}, C_{k}$, and $C_{\varepsilon}$ contours. (a) Contour of $L_{s p} ;(\mathbf{b})$ Contour of $C_{k} ;(\mathbf{c})$ Contour of $C_{\varepsilon}$. 
Based on Figure 11, it can be found that the $C_{k}$ distribution is similar to the $L_{s p}$ distribution. This means that the turbulence kinetic energy strongly influences the near-field noise in pump-turbine. A high $C_{\varepsilon}$ region can be also found in the guide vane jet flow region. However, the high $C_{\varepsilon}$ region is very small in area. Figure 12 shows the $C_{\varepsilon}$ contours on the runner, guide vane, and stay vane leading-edges in a reduced range of $C_{\varepsilon}=0 \sim 1 \times 10^{6}$. In the reduced $C_{\varepsilon}$ range, high $C_{\varepsilon}$ regions can be observed on the leading-edges and almost overlap the high $L_{s p}$ regions in Figure 10.

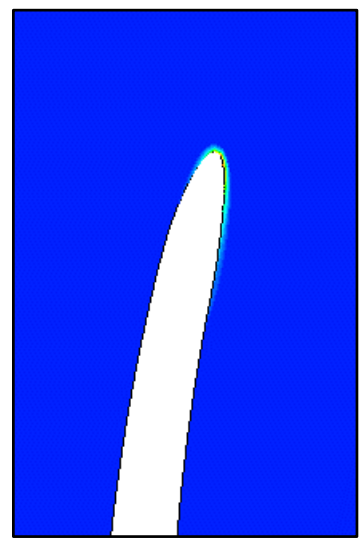

(a)

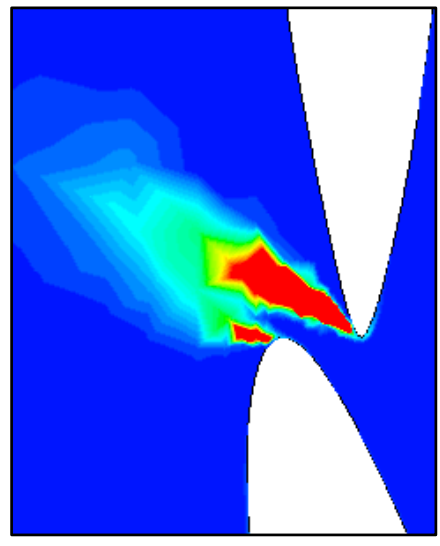

(b)

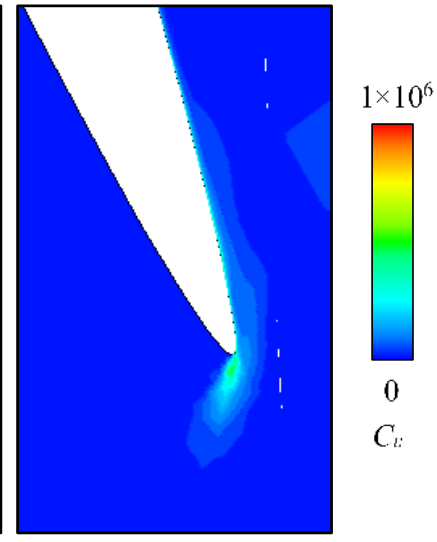

(c)

Figure 12. The contour of $C_{\varepsilon}$ on the blade leading-edges. LE: Leading-edge. (a) Runner leading-edge; (b) Guide vane leading-edge and trailing-edge; (c) Stay vane leading-edge.

Generally, the point of view that high flow noise is strongly related to the flow regime has been proven in this study. The turbulence-induced-noise in vortex is mainly affected by turbulence kinetic energy $k$. For the vortex core region on the number III, V and VII sites, noise increases in the vortex core. For the vortex core region on number IV site, noise decreases in the vortex core. The turbulence-induced-noise in leading-edge separation regions is jointly affected by turbulence kinetic energy $k$ and eddy dissipation rate $\varepsilon$. Hence, the turbulence kinetic energy $k$, which is physically the RMS value of fluctuating velocity, plays the most important role in inducing noise. Further analysis on the transient characteristic of $k$ field is necessary.

\subsection{Turbulence Kinetic Energy Pulsation}

To study the pulsation of turbulence kinetic energy, points were set, as shown in Figure 13, for monitoring the $C_{k}$ variation in the indication regions numbers I to VII. Points $P_{1}$ to $P_{7}$ are, respectively, in the local flow regions I to VII. Figures 1-20 are the time-domain and frequency-domain plots of $C_{k}$ on monitoring points $\mathrm{P}_{1}$ to $\mathrm{P}_{7}$. The time-domain data were acquired within 3600 timesteps that were five runner revolutions. The frequency-domain data was created based on the time-domain data by applying the fast-Fourier transformation (FFT) method with Hanning window. 


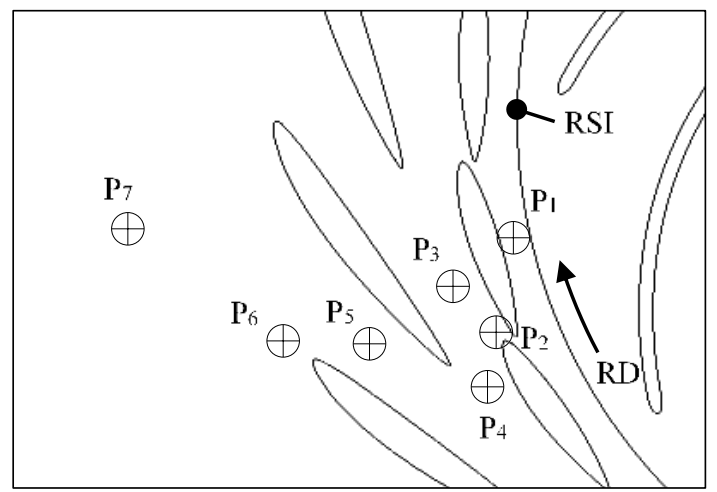

Figure 13. Points $P_{1}$ to $P_{7}$ for monitoring the turbulence flow field. RSI: Rotor-stator interface; RD: Runner rotation direction.

The $C_{k}$ pulsation on $\mathrm{P}_{1}$ is shown in Figure 14. Multiple peaks can be found on the frequency-domain plot. Some important frequencies can be found including the blade frequency $f_{b}$ of about $64.5 \mathrm{~Hz}$ and another frequency $f_{2}$ of about $9.6 \mathrm{~Hz}$. Three peaks are related to the blade frequency $f_{b}$ are, respectively, $f_{b}, 2 f_{b}$, and $3 f_{b}$. Three other peaks are related to $f_{2}$ are $0.15 f_{2}, f_{2}$, and $3 f_{2}$. Generally, $\mathrm{P}_{1}$ is under the strong influence of blade frequency $f_{b}$, which is also a multiple of runner frequency $f_{r n}$. This is because $P_{1}$ is near the runner blade trailing-edge and faces the incoming flow from runner pumping. The frequency $f_{2}$ is also strong and needs further analysis on points $\mathrm{P}_{2}$ to $\mathrm{P}_{7}$.
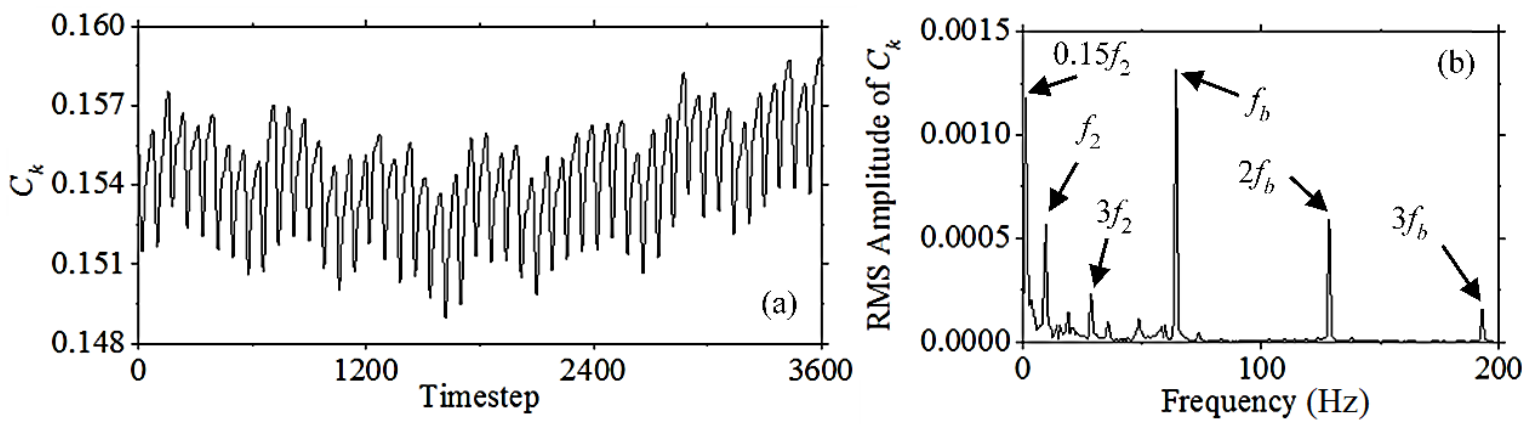

Figure 14. Analysis of $C_{k}$ pulsation on $\mathrm{P}_{1}$. (a) Time-domain plot; (b) frequency-domain plot.

The $C_{k}$ pulsation on $P_{2}$ is shown in Figure 15. The runner blade frequency $f_{b}$ is still obvious and stronger in amplitude than on $P_{1}$. However, the frequency $f_{2}$ and its two-times multiple $2 f_{2}$ are relatively stronger than $f_{b} . \mathrm{P}_{2}$ is in the guide vane jet which is induced by both the runner pumping and the small guide vane opening. Thus, the runner blade frequency impressively influences $\mathrm{P}_{2}$. Frequency $f_{2}$ dominates with the $C_{k}$ peak value up to about 0.23 . Therefore, the $f_{2}$-series frequencies on $P_{1}$ are propagated from the guide vane jet region.
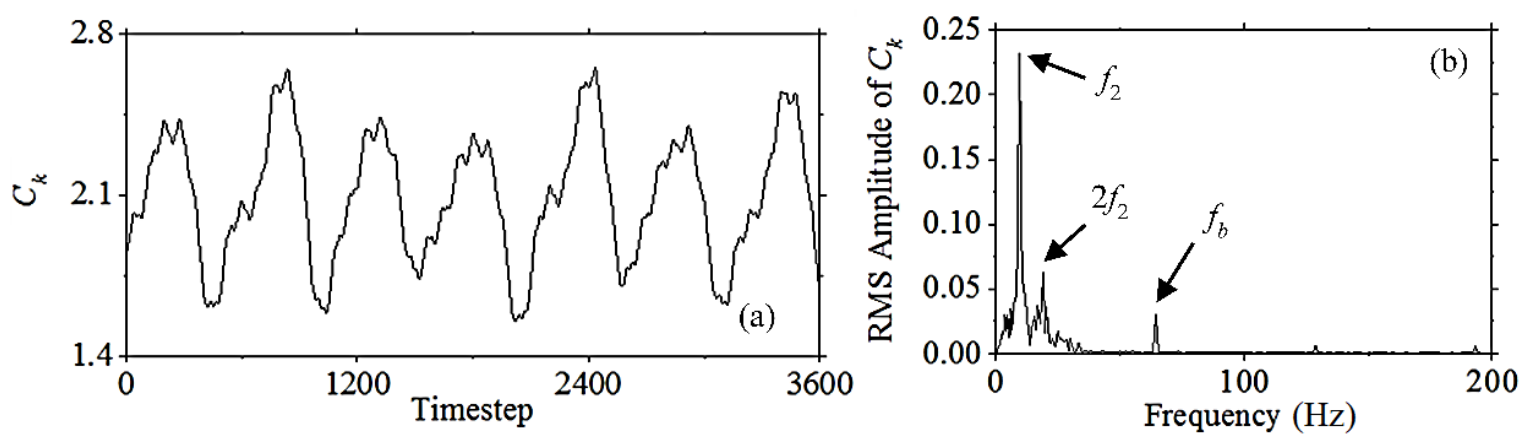

Figure 15. Analysis of $C_{k}$ pulsation on $\mathrm{P}_{2}$. (a) Time-domain plot; (b) frequency-domain plot. 
The $C_{k}$ pulsation on $\mathrm{P}_{3}$ is shown in Figure 16. $\mathrm{P}_{3}$ is in one of the twin-vortexes which rotates in the same direction of runner rotation. The runner blade frequency $f_{b}$ is no longer strong, but $f_{2}$-series dominates. $1 / 3 f_{2}, f_{2}$, and $2 f_{2}$ are on a high amplitude level. Among them, the $C_{k}$ amplitude of $f_{2}$ is the highest that larger than 0.10 . The $C_{k}$ amplitude of $1 / 3 f_{2}$ and $2 f_{2}$ are also higher than 0.05 .
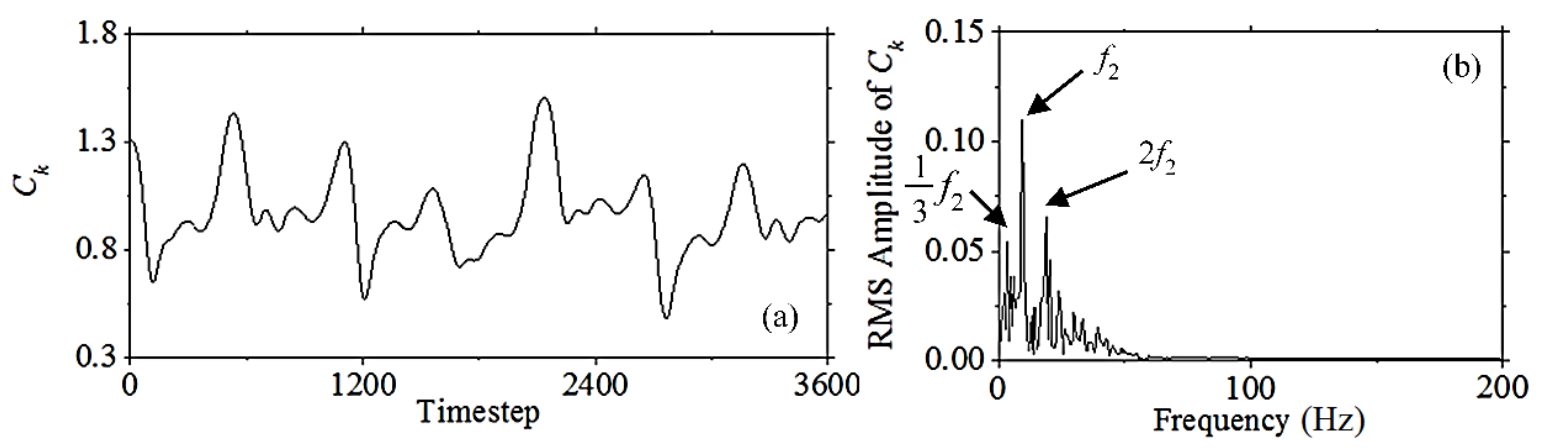

Figure 16. Analysis of $C_{k}$ pulsation on $\mathrm{P}_{3}$. (a) Time-domain plot; (b) frequency-domain plot.

The $C_{k}$ pulsation on $\mathrm{P}_{4}$ is shown in Figure 17. $\mathrm{P}_{4}$ is in another one of the twin-vortexes which rotates counter-rotationally against the runner. Frequency band becomes complex with $1 / 3 f_{2}, f_{2}, 2 f_{2}$, and $5.9 \mathrm{~Hz}$ and $33.6 \mathrm{~Hz}$ peaks. The $C_{k}$ amplitude of these frequencies are no larger than 0.05 and are lower than that on $\mathrm{P}_{3}$. This means that the turbulence kinetic energy is lower in the counter-runner-rotational vortex than in the runner-rotational vortex. According to the $C_{k}$ pulsations on $\mathrm{P}_{3}$ and $\mathrm{P}_{4}$, the $f_{2}$-series frequencies also exist in the twin-vortexes adjacent to the guide vane jet.
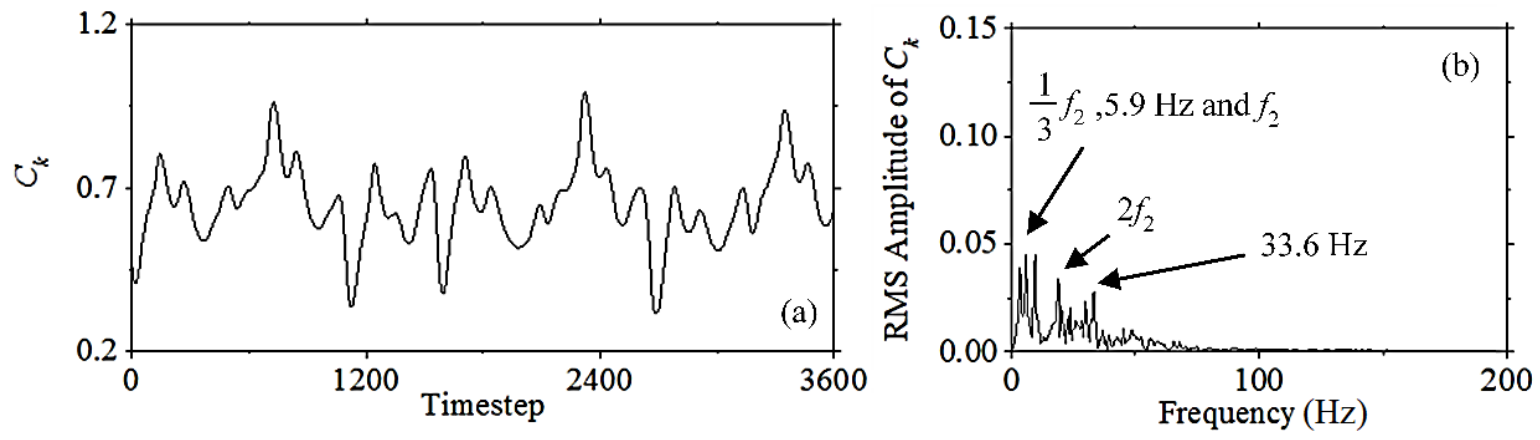

Figure 17. Analysis of $C_{k}$ pulsation on $\mathrm{P}_{4}$. (a) Time-domain plot; (b) frequency-domain plot.

The $C_{k}$ pulsation on $\mathrm{P}_{5}$ is shown in Figure 18. The frequency $f_{2}$ dominates with the $C_{k}$ amplitude of about 0.15 . The frequency $1 / 3 f_{2}$ is also strong with the $C_{k}$ amplitude of about 0.075 . The frequency $2 f_{2}$ is still on the same $C_{k}$ amplitude level as on $\mathrm{P}_{2}, \mathrm{P}_{3}$, and $\mathrm{P}_{4}$.
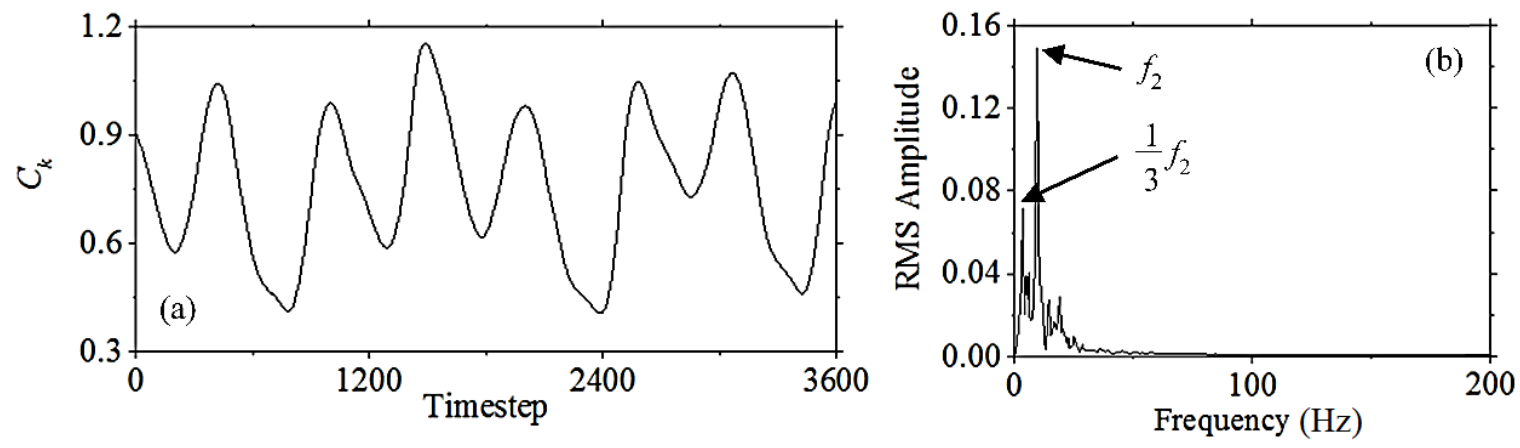

Figure 18. Analysis of $C_{k}$ pulsation on $P_{5}$. (a) Time-domain plot; (b) frequency-domain plot. 
The $C_{k}$ pulsation on $\mathrm{P}_{6}$ is shown in Figure 19. Both the time-domain and frequency domain are similar to $P_{5}$. The $C_{k}$ amplitude of $f_{2}$ increases to about 0.20 on $\mathrm{P}_{6}$, which is stronger than on $\mathrm{P}_{5}$. In the stay vane, the influence of runner blade frequency $f_{b}$ is already very weak and difficult to find on the frequency-domain plots.
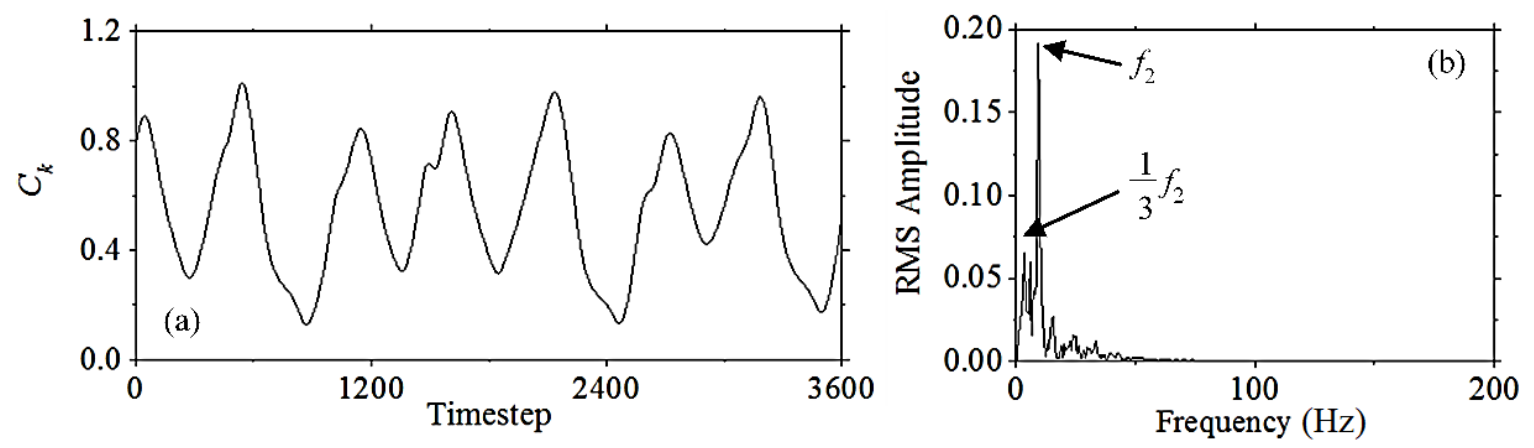

Figure 19. Analysis of $C_{k}$ pulsation on $\mathrm{P}_{6}$. (a) Time-domain plot; (b) frequency-domain plot.

The $C_{k}$ pulsation on $P_{7}$ is shown in Figure 20. The frequencies $1 / 3 f_{2}$ and $f_{2}$ are still strong. The $C_{k}$ amplitude of frequency $f_{2}$ is about 0.20 , which is similar to that on $\mathrm{P}_{6}$. However, the $C_{k}$ amplitude of frequency $1 / 3 f_{2}$ obviously increases to about 0.03 , which is four-times of that on $\mathrm{P}_{6}$. Both $\mathrm{P}_{6}$ and $\mathrm{P}_{7}$ are in the volute, which means that the $1 / 3 f_{2}$ frequency is the dominate frequency in volute.
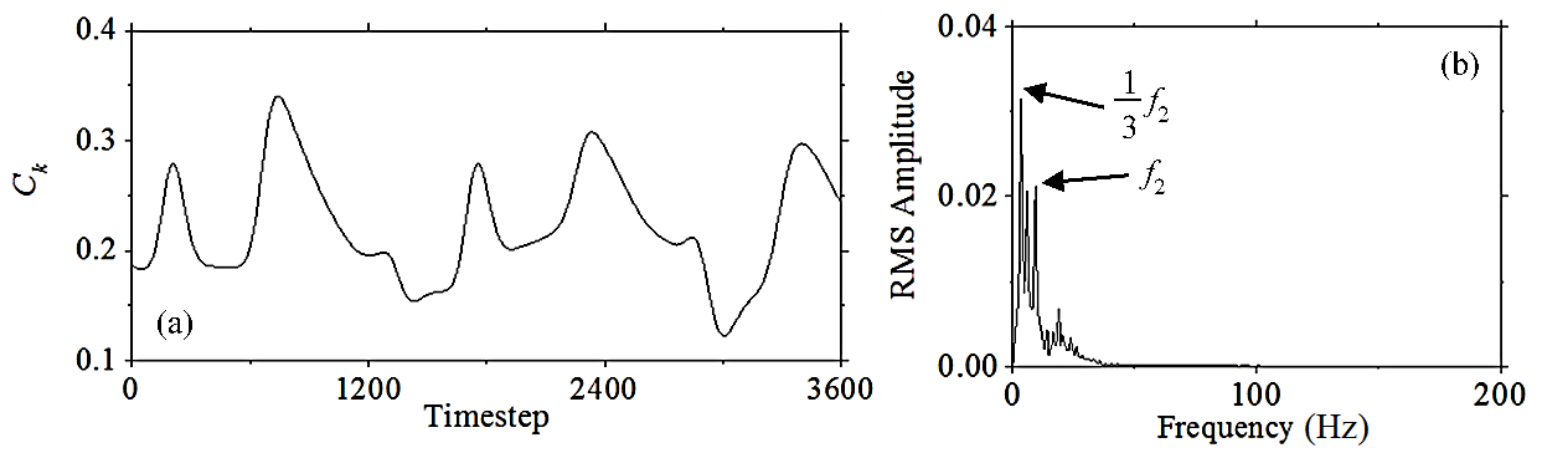

Figure 20. Analysis of $C_{k}$ pulsation on $P_{7}$. (a) Time-domain plot; (b) frequency-domain plot.

Above all, three main $C_{k}$ pulsation frequencies can be found on $\mathrm{P}_{1}$ to $\mathrm{P}_{7}$, as listed in Table 1 . Firstly, the runner blade frequency $f_{b}$ dominates in the region near runner blade. Secondly, the frequency $f_{2}$ above can be defined as $f_{g s v}$ because it dominates, mainly in the guide vane and stay vane region. Thirdly, the frequency $1 / 3 f_{2}$ above can be defined as $f_{v l}$ because it dominates mainly in volute region.

Table 1. The main frequencies of $C_{k}$ pulsation on points $\mathrm{P}_{1}$ to $\mathrm{P}_{7}$.

\begin{tabular}{ccc}
\hline Name & Frequency Value & Description \\
\hline$f_{b}$ & $64.5(\mathrm{~Hz})$ & Runner blade frequency \\
$f_{g s v}$ & $9.6(\mathrm{~Hz})$ & Dominate frequency in guide vane and stay vane. $f_{g s v}=f_{2}$ \\
$f_{v l}$ & $3.2(\mathrm{~Hz})$ & Dominate frequency in volute $f_{v l}=1 / 3 f_{2}$ \\
\hline
\end{tabular}

\subsection{Propagation of Frequency}

To understand the propagation of frequency $f_{b}, f_{g s v}$, and $f_{v l}$ in the flow passage, the $18 \times 18$ flow pulsation tracing topology, as shown in Figure 21, is set instead of the points $P_{1}$ to $P_{7}$. It covers the $1 / 20$ rotational-periodic region including one guide vane passage, one stay vane passage, and a part of the volute passage. Points are ordered as " $1 \sim 18$ " along tangential $\theta$ direction and as "AA RR" along radial 
$R$ direction. $\Delta \theta$ is set as 1 degree, and $\Delta R$ is set as $0.1 \mathrm{~m}$. As the same as on $\mathrm{P}_{1}$ to $\mathrm{P}_{7}$, the frequencies of $C_{k}$ are calculated by applying the Fast-Fourier transformation (FFT) method with Hanning window.

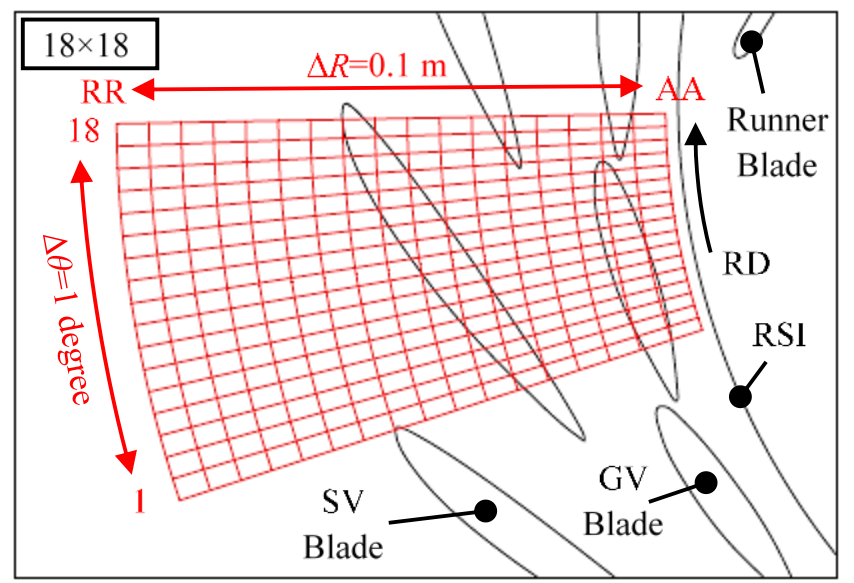

Figure 21. The $18 \times 18$ topology for tracing the frequency propagation. RSI: Rotor-stator interface; RD: Runner rotation direction; GV: Guide vane; SV: Stay vane; 1 18: Order number along tangential direction; AA RR: Order number along radial direction.

In this study, the frequency-dominated turbulence kinetic energy coefficient $C_{k}{ }^{*}$ is defined for $C_{k}$ to understand the propagation of frequency:

$$
C_{k}^{*}=\frac{C_{k R M S}}{\Delta C_{k}}
$$

where $C_{k R M S}$ is the RMS amplitude value of specific frequency. In this case, the $f_{b}=64.5 \mathrm{~Hz}, f_{g s v}=9.6 \mathrm{~Hz}$ and $f_{v l}=3.2 \mathrm{~Hz}$ are tracked using the topology. $\Delta C_{k}$ is the peak-peak value of $C_{k}$ within a specific period. Totally, five runner revolutions were studied in this case. Hence, the parameter $C_{k}{ }^{*}$ can exclude the amplitude difference of local flow pulsation and focus on the frequency character. Figure 22 shows the contour of $C_{k}{ }^{*}$ of $f_{b}=64.5 \mathrm{~Hz}, f_{g s v}=9.6 \mathrm{~Hz}$, and $f_{v l}=3.2 \mathrm{~Hz}$. The color from blue to red denotes the amplitude of $C_{k}{ }^{*}$. The blank sites are guide vane blades and stay vane blades. In Figure 22, parameter $R$ is the radial position. Four copies are plotted based on the original $18 \times 18$ topology to have a better blade-to-blade view in $\theta=0 \sim 90^{\circ}$.

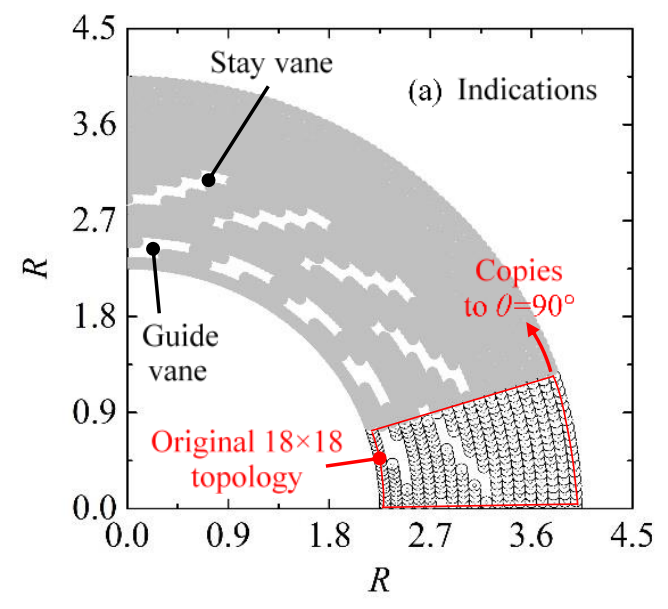

(a)

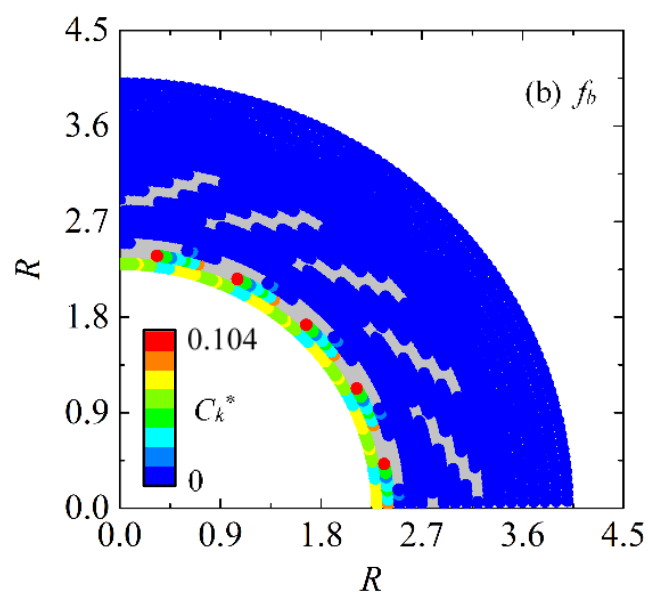

(b)

Figure 22. Cont. 


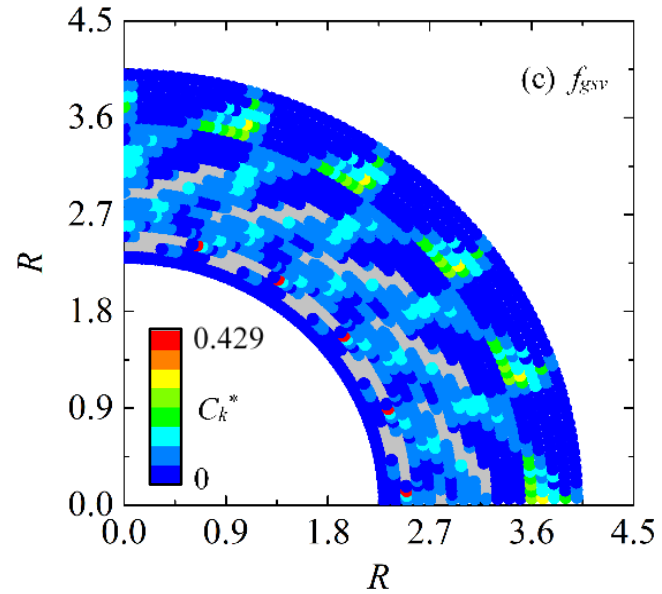

(c)

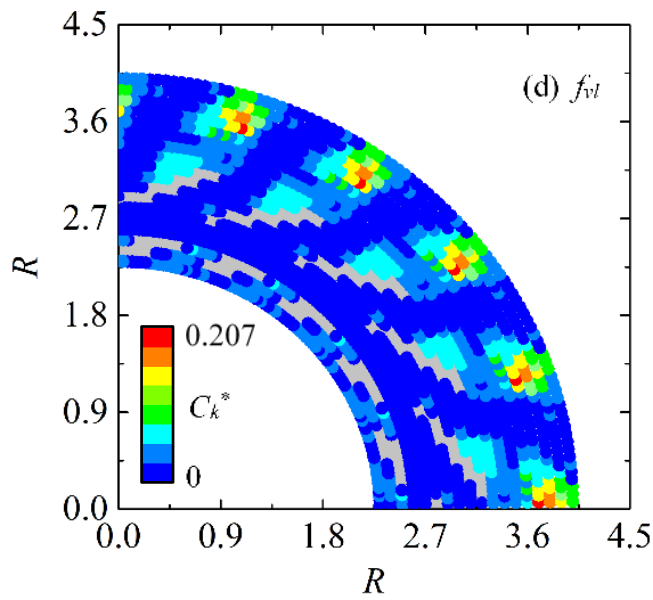

(d)

Figure 22. Contour of $C_{k}{ }^{*}$ of $f_{b}=64.5 \mathrm{~Hz}, f_{g s v}=9.6 \mathrm{~Hz}$ and $f_{v l}=3.2 \mathrm{~Hz}$. (a) Indications; (b) Contour of $f_{b} ;(\mathbf{c})$ Contour of $f_{g s v} ;(\mathbf{d})$ Contour of $f_{v l}$.

As shown in Figure 22b, the runner blade frequency $f_{b}$ mainly affects $C_{k}{ }^{*}$ in the region between the runner and guide vane. The highest $C_{k}{ }^{*}$ site locates at the front side of the guide vane blade. In the stay vane and volute, the influence of $f_{b}$ on $C_{k}{ }^{*}$ is very weak. According to Figure 22c, the dominate frequency in the guide vane and stay vane $f_{g s v}$ has a high $C_{k}{ }^{*}$ value everywhere in the vane channels. The highest $C_{k}{ }^{*}$ value of $f_{g s v}$ is in the guide vane jet region, which is between two guide vane blades. A wide high $C_{k}^{*}$ region can be also found in the volute near the stay vane outlet. Based on Figure 22d, the dominate frequency in volute $f_{v l}$ has very strong influence on $C_{k}{ }^{*}$ in volute. The highest $C_{k}{ }^{*}$ sites are between the two stay vane jets and overlap the volute vortex sites. More high $C_{k}{ }^{*}$ regions of $f_{v l}$ are on the back side of the stay vane blade. The region in the guide vane jet is also high in $C_{k}{ }^{*}$ under the influence of frequency $f_{v l}$.

Generally, the strongly influenced region by $f_{b}=64.5 \mathrm{~Hz}, f_{g s v}=9.6 \mathrm{~Hz}$, and $f_{v l}=3.2 \mathrm{~Hz}$ can be summarized as follows:

- $f_{b}=64.5 \mathrm{~Hz}$ : (a) Between runner and guide vane; (b) in the guide vane jet;

- $f_{g s v}=9.6 \mathrm{~Hz}$ : (a) In the stay vane and guide vane channels; (b) near volute vortex; (c) in the guide vane jet;

- $\quad f_{v l}=3.2 \mathrm{~Hz}$ : (a) Near volute vortex; (b) on the back side of stay vane blade; (c) in the guide vane jet.

The specific frequencies of flow characteristics are induced by different flow structures. The high amplitude sites of specific frequencies relate to the distribution of flow structures. However, the specific frequencies of turbulent flow may propagate in fluid and influence adjacent regions.

\subsection{Checking the Effectiveness of DES}

To check the effectiveness of DES, the contour of the DES blending function is plotted in Figure 23. In regions where the DES blending function is 0 , the LES model is activated. In the region where the DES blending function is 1 , the RANS model is activated. On $S_{A}$, it can be seen that the LES model is activated in the runner blade trailing-edge wake, inter guide vane jet, stay vane leading-edge separation region, stay vane trailing-edge wake, and volute vortex. On $\mathrm{S}_{\mathrm{B}}$, the core region in the volute, which is the two symmetrical rotating flow structures' interaction site, is simulated by the LES model. In these jet and vortex flow regions, the LES model helps to provide a better resolution of turbulent flow. It proves that DES is effective in this study with jet-vortex flow structure from runner outlet to volute. 

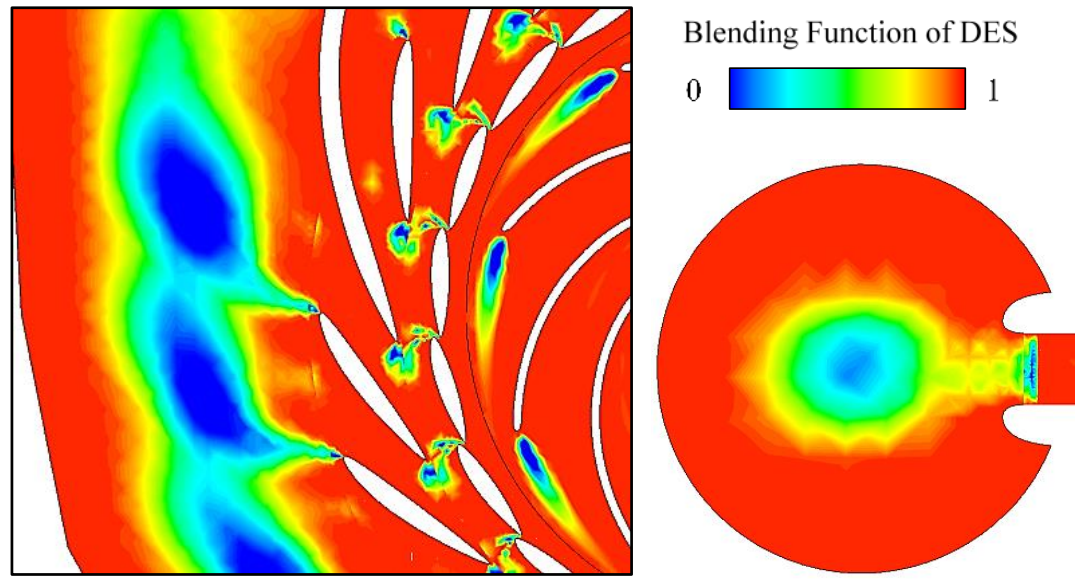

Figure 23. Checking the blending function of the Detached Eddy Simulation (DES) on $\mathrm{S}_{\mathrm{A}}$ and in the specific region on $\mathrm{S}_{\mathrm{B}}$.

\section{Conclusions}

According to the studies above, conclusions can be drawn as follows:

(1) In a pump-turbine's start-up process in pump mode, flow regime is undesirable due to a small guide vane opening angle. In this study at $C_{\varphi}=0.015$ and $\alpha=3$ degrees, the jet-vortex flow structure can be observed in the diffuser, including the guide vane, stay vane, and volute. It consists of I-the flow ring between the runner trailing-edge and the guide vane, II-the guide vane jet, III and IV—-the twin-vortexes adjacent to guide vane jet, V-the inter stay vane vortex, VI - the stay vane jet, and VII — the volute vortex-ring. These jets and vortexes interfere with the runner pumping and cause an instability of the flow field.

(2) Based on the acoustic analogy method, strong noise can be found in the jet-vortex flow structure. Results show that the high turbulence kinetic energy and eddy dissipation caused by undesirable flow structures could be the reason why noise is generated in the flow passages. High sound power level $L_{s p}$ regions in the jets and vortexes are caused by high turbulence kinetic energy. High $L_{s p}$ regions on the blade leading-edges are due to local flow striking and separation with strong eddy dissipation. The strongest $L_{s p}$ region is in the guide vane jet, where $L_{s p}$ is up to about $150 \mathrm{~dB}$. This shows that the guide vane opening and direction are the most important factors in inducing noise, especially at small guide vane opening angle conditions.

(3) The pulsation of turbulence kinetic energy coefficient $C_{k}$ was studied on monitoring points $\mathrm{P}_{1}$ to $P_{7}$. Three specific frequencies were found, including the runner blade frequency $f_{b}=64.5 \mathrm{~Hz}$, the dominate frequency in the guide vane and stay vane $f_{g s v}=9.6 \mathrm{~Hz}$, and the dominate frequency in the volute $f_{v l}=3.2 \mathrm{~Hz}$. The $18 \times 18$ flow pulsation tracing topology gives a better visualization of frequency distribution and propagation. The frequency-dominated turbulence kinetic energy coefficient $C_{k}^{*}$ was used instead of $C_{k}$ to exclude the pulsation amplitude difference. Results show that different specific frequencies are caused by different flow structures. Frequencies will propagate and affect the adjacent regions.

Generally, the guide vane opening angle is found crucial in producing flow noise and turbulence pulsations, especially in the pump mode's start-up process. A better understanding of the flow regime at the small guide vane opening can help reducing and optimizing the flow noise in the future researches. In this study, the numerical study was done on a prototype scale, but the experimental study was conducted on a model scale. In the future, the tests will be done on a prototype pump-turbine unit to have a better comparative analyses.

Author Contributions: Conceptualization, R.T.; methodology, R.T.; investigation, R.T. and Z.W.; writing-original draft preparation, R.T.; writing-review and editing, Z.W.; supervision, Z.W.; project administration, R.T. and Z.W. 
Funding: This research was funded by China Postdoctoral Science Foundation, grant number 2018M640126 and National Natural Science Foundation of China, grant number 51439002. The APC was funded by China Postdoctoral Science Foundation, grant number 2018M640126.

Acknowledgments: The authors would acknowledge Faye Jin and Ruofu Xiao in China Agricultural University for their supports given during this research.

Conflicts of Interest: The authors declare no conflict of interest.

\section{Nomenclature}

\section{Latin letters}

$C_{1}$ the studied condition $C_{\varphi}=0.015$ and $C_{\alpha}=0.096 n_{q}$

$C_{D E S} \quad$ model constant of DES $P$

$C_{k} \quad$ turbulence kinetic energy coefficient

$C_{k}^{*} \quad$ frequency-dominated $C_{k}$

$\begin{array}{lll}C_{k R M S} & \text { RMS amplitude value of specific frequency } & Q_{d} \\ C_{v} & \text { velocity coefficient } & R\end{array}$

$C_{\alpha} \quad$ relative guide vane opening angle

$C_{\varepsilon} \quad$ eddy dissipation rate coefficient

$C_{\varphi} \quad$ flow rate coefficient

$C_{\varphi B E P} \quad$ flow rate coefficient at best efficiency point

$\mathrm{C}_{\omega}$ production term coefficient in turbulence model $\bar{S}_{i j}$

$F_{1} \quad$ blending function of SST model

$f_{2} \quad$ a specific frequency

$f_{b} \quad$ runner blade frequency $\quad U_{h i}$

$f_{g s v} \quad$ dominate frequency in guide vane and stay vane $V_{c}$

$f_{v l} \quad$ dominate frequency in volute $V_{r e l}$

$g$ acceleration of gravity $W_{A}$

$H_{d} \quad$ head at best efficiency point $\quad W_{\text {ref }}$

$k \quad$ turbulence kinetic energy

$l_{k-\omega} \quad$ turbulence scale

$L_{s p} \quad$ turbulent-flow-induced sound power level

$n_{d} \quad$ runner rotation speed

\section{Greek letters}

$\alpha_{\varepsilon} \quad$ constant in acoustic analogy method

$\beta_{k} \quad$ model constant of SST model

$\Delta C_{k} \quad$ peak-peak value of $C_{k}$

$\delta_{i j} \quad$ Kroneker delta

$\Delta_{m} \quad$ mesh length scale

$\Delta R \quad$ radial interval in pulsation tracing topology

specific speed

production term in turbulence model

flow rate

$Q_{d} \quad$ flow rate at best efficiency point

$R \quad$ radial direction

$R_{h i} \quad$ radius at runner high pressure side

$R_{\text {lowh }} \quad$ radius at runner low pressure side at hub

$R_{\text {lows }} \quad$ radius at runner low pressure side at shroud

$\mathrm{S}_{\mathrm{A}}, \mathrm{S}_{\mathrm{B}} \quad$ reference surfaces for flow analysis

mean rate of strain tensor

time

velocity

$U_{h i} \quad$ rotational linear velocity at $R_{h i}$

sound speed in fluid medium

relative velocity

turbulent-flow-induced sound power

ref reference sound power

$X, Y, Z$ orthogonal coordinate components

$y^{+} \quad$ dimensionless height off-wall

$\begin{array}{ll}\Delta x / y / z & \text { side length of mesh element } \\ \Delta \theta & \text { tangential interval in pulsation tracing topology }\end{array}$

$\varepsilon \quad$ eddy dissipation rate

Acronyms

BEP best efficiency point

CA computational acoustic

CFD computational fluid dynamics

DES detached eddy simulation

DT draft tube

FFT fast-Fourier transformation

GCI grid convergence index

GV guide vane

$\eta \quad$ efficiency

LES large-eddy simulation

MRF multiple reference frame

$\theta \quad$ tangential direction

$\mu \quad$ dynamic viscosity

$\mu_{t} \quad$ eddy viscosity

$\rho \quad$ density

$\sigma_{k} \quad$ model constant of SST model SST

$\sigma_{\omega} \quad$ model constant of SST model SV

$\omega \quad$ rotational angular speed

RANS Reynolds-averaged Navier-Stokes

RMS root-mean-square

$\mathrm{RN}$ runner

RSI rotor stator interaction

ShT shear stress transport

SV stay vane

VL volute

\section{References}

1. Oishi, A.; Yokoyama, T. Development of high head single and double stage reversible pump-turbines. In Proceedings of the 10th IAHR Symposium on Hydraulic Machinery and Cavitation, Tokyo, Japan, 28 September-2 October 1980.

2. Mei, Z. Technology of Pumped-Storage Power Generation; China Machine Press: Beijing, China, 2000. 
3. Rodriguez, C.G.; Mateosprieto, B.; Egusquiza, E. Monitoring of rotor-stator interaction in pump-turbine using vibrations measured with on-board sensors rotating with shaft. Shock Vib. 2014, 276796. [CrossRef]

4. Hasmatuchi, V.; Farhat, M.; Roth, S.; Botero, F.; Avellan, F. Experimental evidence of rotating stall in a pump-turbine at off-design conditions in generating mode. J. Fluids Eng. 2011, 133, 051104. [CrossRef]

5. Zhang, Y.; Zhang, Y.; Wu, Y. A review of rotating stall in reversible pump turbine. Proc. Inst. Mech. Eng. Part C J. Mech. Eng. Sci. 2017, 231, 1181-1204. [CrossRef]

6. Zuo, Z.; Liu, S.; Sun, Y.; Wu, Y. Pressure fluctuations in the vaneless space of High-head pump-turbines-A review. Renew. Sustain. Energy Rev. 2015, 41, 965-974. [CrossRef]

7. Li, Z.; Bi, H.; Karney, B.; Wang, Z.; Yao, Z. Three-dimensional transient simulation of a prototype pump-turbine during normal turbine shutdown. J. Hydraul. Res. 2017, 55, 520-537. [CrossRef]

8. Review and outlook of studying on noise of centrifugal pumps. J. Vib. Shock 2011, 30, 77-84.

9. Govern, C.C.; TenWolde, P.R. Energy dissipation and noise correlations in biochemical sensing. Phys. Rev. Lett. 2014, 113, 258102. [CrossRef]

10. Bernd, D.; Wurm, F.H. Noise sources in centrifugal pumps. In Proceedings of the 2nd WSEAS International Conference on Applied and Theoretical Mechanics, Venice, Italy, 20-22 November 2006.

11. Langthjem, M.A.; Olhoff, N. A numerical study of flow-induced noise in a two-dimensional centrifugal pump. Part II. Hydroacoustics. J. Fluids Struct. 2004, 19, 369-386. [CrossRef]

12. Chudina, M. Noise as an indicator of cavitation in a centrifugal pump. Acoust. Phys. 2003, 49, $463-474$. [CrossRef]

13. Curle, N. The influence of solid boundaries upon aerodynamic sound. Proc. R. Soc. Lond. Ser. A Math. Phys. Sci. 1955, 231, 505-514.

14. Ffowcs-Williams, J.E.; Hawkings, D.L. Sound generation by turbulence and surfaces in arbitrary motion. Math. Phys. Sci. 1969, 264, 321-342. [CrossRef]

15. Goldstein, J.L. An optimum processor theory for the central formation of the pitch of complex tones. J. Acoust. Soc. Am. 1973, 54, 1496-1516. [CrossRef] [PubMed]

16. Lighthill, M.J. On sound generated aerodynamically, II. Turbulence as a source of sound. Proc. R. Soc. Lond. Ser. A 1954, 222, 1-32.

17. Chu, S.; Dong, R.; Katz, J. Relationship between unsteady flow, pressure fluctuations, and noise in a centrifugal pump, part B: Effects of blade-tongue interaction. J. Fluids Eng. 1995, 117, 30-35. [CrossRef]

18. Srivastav, O.P.; Pandu, K.R.; Gupta, K. Effect of radial gap between impeller and diffuser on vibration and noise in a centrifugal pump. J. Inst. Eng. Mech. Eng. Div. 2003, 84, 36-39.

19. Sun, X.; Hu, Z.; Feng, Y.; Zhou, S. An aeroacoustic model about the rotating stall of a compressor. Acta Aeronaut. Astronaut. Sin. 1991, 12, A467-A473.

20. Mongeau, L.; Thompson, D.E.; Mclaughlin, D.K. Sound generation by rotating stall in centrifugal turbomachines. J. Sound Vib. 1993, 163, 1-30. [CrossRef]

21. Bogey, C.; Marsden, O.; Bailly, C. Large-eddy simulation of the flow and acoustic fields of a Reynolds number $10^{5}$ subsonic jet with tripped exit boundary layers. Phys. Fluids 2011, 23, 035104. [CrossRef]

22. Canepa, E.; Cattanei, A.; Zecchin, F.M.; Milanese, G.; Parodi, D. An experimental investigation on the tip leakage noise in axial-flow fans with rotating shroud. J. Sound Vib. 2016, 375, 115-131. [CrossRef]

23. Brooks, T.F.; Hodgson, T.H. Trailing edge noise prediction from measured surface pressures. J. Sound Vib. 1981, 78, 69-117. [CrossRef]

24. Wang, W.; Thomas, P.J. Acoustic improvement of stator-rotor interaction with nonuniform trailing edge blowing. Appl. Sci. 2018, 8, 994. [CrossRef]

25. Proudman, I. The generation of noise by isotropic turbulence. Proc. R. Soc. Lond. Ser. A Math. Phys. Sci. 1952, 214, 119-132.

26. Tao, R.; Zhao, X.; Wang, Z. Evaluating the transient energy dissipation in a centrifugal impeller under rotor-stator interaction. Entropy 2019, 21, 271. [CrossRef]

27. Liu, J.; Wang, L.; Liu, S.; Sun, Y.; Wu, Y. Three dimensional flow simulation of load rejection of a prototype pump-turbine. Eng. Comput. 2013, 29, 417-426.

28. Nennemann, B.; Parkinson, É. Yixing pump turbine guide vane vibrations: Problem resolution with advanced CFD analysis. IOP Conf. Ser. Earth Environ. Sci. 2010, 12, 012057. [CrossRef]

29. Zhu, D.; Xiao, R.; Tao, R.; Liu, W. Impact of guide vane opening angle on the flow stability in a pump-turbine in pump mode. Proc. Inst. Mech. Eng. Part C J. Mech. Eng. Sci. 2017, 231, 2484-2492. [CrossRef] 
30. Li, D.; Gong, R.; Wang, H.; Han, 1.; Wei, X.; Qin, D. Analysis of vorticity dynamics for hump characteristics of a pump turbine model. J. Mech. Sci. Technol. 2016, 30, 3641-3650. [CrossRef]

31. Tao, R.; Xiao, R.; Wang, F.; Liu, W. Cavitation behavior study in the pump mode of a reversible pump-turbine. Renew. Energy 2018, 125, 655-667. [CrossRef]

32. Gentner, C.; Sallaberger, M.; Widmer, C.; Braun, O.; Staubli, T. Numerical and experimental analysis of instability phenomena in pump turbines. IOP Conf. Ser. Earth Environ. Sci 2012, 15, 032042. [CrossRef]

33. Liu, J.; Liu, S.; Wu, Y.; Sun, Y.; Zuo, Z. Prediction of "S" characteristics of a pump-turbine with small opening based on V2F model. Int. J. Mod. Phys. Conf. Ser. 2012, 19, 417-423. [CrossRef]

34. Spalart, P.R. Detached-eddy simulation. Annu. Rev. Fluid Mech. 2009, 41, 181-202. [CrossRef]

35. Menter, F.R. Two-Equation Eddy-Viscosity Turbulence Models for Engineering Applications. AIAA J. 1994, 32, 1598-1605. [CrossRef]

36. Liu, H.; Tan, M. Modern Design Methods for Centrifugal Pumps; China Machine Press: Beijing, China, 2013.

37. Celik, I.; Ghia, U.; Roache, P.J.; Freitas, C.J.; Coloman, H.; Raad, P.E. Procedure of estimation and reporting of uncertainty due to discretization in CFD applications. J. Fluids Eng. 2008, 130, 078001.

38. Kader, B.A. Temperature and concentration profiles in fully turbulent boundary layers. Int. J. Heat Mass Transf. 1981, 24, 1541-1544. [CrossRef]

39. Shankaran, G.; Dogruoz, M.B. Advances in fan modeling-Using multiple reference frame (MRF) approach on blowers. In Proceedings of the ASME 2011 Pacific Rim Technical Conference \& Exposition on Packaging and Integration of Electronic and Photonic Systems, Portland, OR, USA, 6-8 July 2011.

(C) 2019 by the authors. Licensee MDPI, Basel, Switzerland. This article is an open access article distributed under the terms and conditions of the Creative Commons Attribution (CC BY) license (http://creativecommons.org/licenses/by/4.0/). 